University of Wollongong

Research Online

Faculty of Engineering and Information

Faculty of Engineering and Information

Sciences - Papers: Part A

Sciences

$1-1-2014$

Behaviour of hollow core square reinforced concrete columns wrapped with CFRP with different fibre orientations

Muhammad N. Hadi

University of Wollongong, mhadi@uow.edu.au

T D. Le

University Of Wollongong

Follow this and additional works at: https://ro.uow.edu.au/eispapers

Part of the Engineering Commons, and the Science and Technology Studies Commons

Research Online is the open access institutional repository for the University of Wollongong. For further information contact the UOW Library: research-pubs@uow.edu.au 


\title{
Behaviour of hollow core square reinforced concrete columns wrapped with CFRP with different fibre orientations
}

\begin{abstract}
Results of testing twelve hollow core square reinforced concrete columns wrapped with Carbon fibre 33 reinforced polymer (CFRP) are presented. The effect of fibre orientation on the performance of specimens 34 under concentric and eccentric loads was investigated. Twelve specimens were divided into four groups with three 36 specimens each. The specimens in the first reference group were unwrapped, while the specimens in the 37 remaining groups were wrapped with CFRP of different wrap combinations of three fibre orientations. The specimens in each group were tested 39 under three eccentricities: 0 (concentric), 25, and $50 \mathrm{~mm}$ up to failure. Test results show that all wrap- 40 ping configurations increased both the strength and ductility of hollow core square reinforced concrete 41 columns. However, the increase of compressive strength was marginal. The columns, which were 42 wrapped exclusively with hoop configuration, proved to have the greatest ductility. Axial load-bending 43 moment P- M interaction diagrams of each group were drawn based on the experimental results and 44 compared with theoretical calculations.
\end{abstract}

\section{Keywords}

cfrp, different, fibre, orientations, core, square, behaviour, reinforced, hollow, concrete, columns, wrapped

Disciplines

Engineering | Science and Technology Studies

\section{Publication Details}

Hadi, M. N. \& Le, T. D. (2014). Behaviour of hollow core square reinforced concrete columns wrapped with CFRP with different fibre orientations. Construction and Building Materials, 50 (January), 62-73. 


\title{
Behaviour of Hollow Core Square Reinforced Concrete Columns Wrapped with CFRP with Different Fibre Orientations
}

\author{
M.N.S. Hadi and T.D. Le \\ School of Civil, Mining and Environmental Engineering, University of Wollongong, \\ Wollongong, NSW 2522, Australia
}

\section{Research Highlights}

This paper presents results of testing twelve reinforced concrete hollow core columns wrapped with FRP. The aim of the tests was to investigate the effect of fibre orientation on the behavior of these columns. All the specimens were made of reinforced concrete with the same amount of internal steel reinforcement and were designed according to the requirements of the Australian Standard AS 3600-2009. The specimens had square cross-section with 200 mm side dimension, $800 \mathrm{~mm}$ height, and a $80 \times 80 \mathrm{~mm}$ hole at their center. All corners of the specimens were rounded to $32 \mathrm{~mm}$ radius to prevent premature failure of FRP wraps due to stress concentration. The columns were tested under different eccentricities.

The following conclusions are drawn:

The fibre in the hoop direction can significantly increase the ductility of hollow core square reinforced concrete columns under concentric or eccentric loading. However, the increment of the compressive strength of FRP-confined hollow core columns is marginal.

The combination of $\pm 45^{\circ}$ oriented CFRP layers and one hoop layer was expected to have the largest ductility. However, it did not show any significant increase in deflections of the columns under both concentric and eccentric testing. 
The analysis of results showed that the stress-strain model developed by Mander at al. (1998) for solid rectangular columns is applicable for hollow core columns wrapped with FRP. The model results are agreeable with the experimental results. 
6 Abstract:

\section{Behaviour of Hollow Core Square Reinforced Concrete Columns Wrapped with CFRP with Different Fibre Orientations}

\author{
M.N.S. Hadi ${ }^{*}$ and T.D. Le \\ School of Civil, Mining and Environmental Engineering, University of Wollongong, \\ Wollongong, NSW 2522, Australia
}

\begin{abstract}
7 Results of testing twelve hollow core square reinforced concrete columns wrapped with 8 Carbon fibre reinforced polymer (CFRP) are presented. The effect of fibre orientation on the 9 performance of specimens under concentric and eccentric loads was investigated. Twelve specimens (200 mm x $200 \mathrm{~mm}$ in cross-section, $800 \mathrm{~mm}$ in height and having an $80 \mathrm{~mm}$ square hole) were divided into four groups with three specimens each. The specimens in the first reference group were unwrapped, while the specimens in the remaining groups were wrapped with CFRP of different wrap combinations of three fibre orientations $\left(0^{\circ}, 45^{\circ}\right.$, and $90^{\circ}$ with respect to the circumferential direction). The specimens in each group were tested under three eccentricities: 0 (concentric), 25, and $50 \mathrm{~mm}$ up to failure. Test results show that all wrapping configurations increased both the strength and ductility of hollow core square reinforced concrete columns. However, the increase of compressive strength was marginal. The columns, which were wrapped exclusively with hoop configuration, proved to have the greatest ductility. Axial load-bending moment P-M interaction diagrams of each group were drawn based on the experimental results and compared with theoretical calculations.
\end{abstract}

\footnotetext{
* Corresponding author. Tel.: +61-2-4221-4762; fax +61-2-4221-3238.

E-mail address: mhadi@uow.edu.au
} 
1

\section{Introduction}

2 Several studies have shown that fibre reinforced polymer (FRP) is efficient in

3 strengthening concrete columns for both strength and ductility. These studies mostly focused

4 on testing solid cross-section columns, which are wrapped with FRP in the hoop direction.

5 When the concrete is subjected to axial compression, it tends to expand. This lateral 6 expansion is restrained by the activation of FRP stressing in tension. Thereby, FRP-confined 7 concrete core of solid section columns is subjected to triaxial compression, which increases 8 the strength of concrete. In addition, FRP delays the failure of concrete core leading to 9 increasing the column's ductility. Meanwhile the response of hollow core columns under 10 compressive loading is significantly different from that of solid columns due to the existence 11 of a void part. The concrete in a FRP-confined hollow core column is in a state of biaxial stress. As the strength of FRP is much greater than the capacity of the concrete core, under large loads the concrete may crumple inwardly resulting in an ineffective confinement.

14 Review of literature shows that limited numbers of studies were undertaken to investigation 15 the behaviour of hollow core columns, especially for hollow core non-circular cross-sections 16 in which the confinement pressure is non-uniform and complicated. This paper deals with 17 hollow core square reinforced concrete column, and fibre orientation is the main study 18 parameter. The variation in fibre orientation that affects the strength, ductility and failure 19 modes of the specimens was studied and discussed herein.

\subsection{FRP in strengthening solid core columns}

21 Wrapping FRP transversely with respect to column's axial axis was mostly used in 22 previous studies. These studies proved that circumferential FRP wraps provide considerable 23 confinement pressure to the concrete core under compressive loads delaying the crushing of 24 concrete and buckling of longitudinal steel reinforcement, as a result, increasing the 
1 compressive strength and deformation capacity of the column. However, these enhancements

2 are only achieved when a column is tested concentrically or when the eccentricity of the load

3 is small. When the eccentricity is large, the load carrying capacity is significantly reduced

4 because both axial action and bending action are induced. Li and Hadi [1], Hadi [2,3]

5 conducted experiments on circular concrete columns under different eccentricities. Results of

6 these studies show that external confinement with FRP improves the performance of columns

7 under eccentric loading. However, while the gain in ductility was distinctive, the strength

8 was only enhanced to some extent when an eccentric load was applied. In fact, under

9 eccentric compressive loading, columns bend producing an additional bending moment 10 (secondary moment) on the column. The increase in the applied load results in lateral 11 deflection increases and the total eccentricity of the applied load is thereby increased. This in 12 turn increases the internal moment of the column and causes compressive strength capacity 13 reduction.

14 FRP confinement leads to greater slenderness in the column [4], leading to increased lateral bending acting on the column. To resist such bending moment, vertical FRP layers were added. The author concluded that the adding vertical CFRP straps improved significantly the performance of the columns for both strength and ductility under eccentric loading. Hadi and Widiarsa [6] conducted an experimental program on solid, square, 21 reinforced concrete columns, and similar results were reported. In fact, the benefit of longitudinal wraps is more obvious with the increase in eccentricity. Tan [7] also confirmed that increasing the amount of longitudinal fibre sheets leads to enhancement in strength and

24 ductility of the solid, square, concentrically loaded columns. However, this increase would be 
1 sheets.

2 Wrapping FRP in other directions was also studied by several researchers. Rochette and

3 Labossiere [8] used fibres oriented at $\pm 15^{\circ} / 0^{\circ}$ to wrap square concrete columns. Mirmiran and

4 Shahawy [9] applied $\pm 15^{\circ}$ fibres from the hoop direction in their concrete-filled FRP tubes. In

5 the study by Pessiki et al. [10], $0^{\circ} \pm 45^{\circ}$ oriented fibres were used to wrap both small and large

6 scale square and circular concrete columns. However, these specimens were not extensively 7 analyzed in both strength and ductility aspects. Li et al. [11] tested concentrically FRP8 confined concrete cylinders (152.4 mm diameter and $304.8 \mathrm{~mm}$ height) to study the effect of 9 fibre orientation on their structural behaviour. A variety of fibre orientations with different 10 thicknesses were used in their study. It was found that the strength, ductility, and failure 11 mode of the confined cylinders depend on the CFRP wrapping orientation and layer 12 thickness. Wrapping FRP at a certain angle in between the hoop direction and the vertical 13 direction may result in strength lower than that of a column wrapped with FRP in the hoop 14 direction only. Specimens wrapped with $45^{\circ}$ FRP showed a slight increase in the axial strain. 15 As stated by the authors, the main reason for this slight increase in axial displacement was 16 insufficient provision of FRP. Sadeghian et al. [12] also investigated the effect of fibre 17 orientation on concrete cylinders $(150 \mathrm{~mm}$ diameter and $300 \mathrm{~mm}$ height) under uniaxial 18 compressive loading. They concluded that longitudinal fibres have no significant effect on analysis method to study the behaviour of FRP-confined concrete columns for changes in 24 FRP ply configuration. The authors concluded that the rate of increase in ductility is highest 
1 for fibre oriented at an angle other than the hoop and longitudinal orientations. This is

2 noteworthy as the ductility is an important parameter of a member allowing the material to

3 undergo large plastic deformation without failure in a brittle and abrupt manner, particularly 4 during large earthquakes where forces are expected to exceed the yield strength of the 5 material.

\section{$6 \quad 1.2$ FRP in strengthening hollow core columns}

7 Recently, several studies have investigated hollow core columns. Lignola et al. [16] 8 conducted a study on hollow square columns wrapped with CFRP in the hoop direction and 9 tested them under various eccentricities. The test results showed that horizontally oriented 10 wraps could improve strength and ductility of hollow core square columns under eccentric 11 loading. However, the strength enhancement was more pronounced for specimens loaded 12 with a smaller eccentricity. Ductility increases with the increase of eccentricity. Yazici and Hadi [17] performed a study on hollow core circular concrete columns. CFRP layers in the 14 transverse direction were also used in their experiments to wrap specimens. Similar conclusions were drawn by the authors that strength improvement of CFRP wrapped columns under concentric load was higher than eccentrically loaded CFRP wrapped columns. When 17 eccentricity was larger, the increase in strength was reduced meanwhile that for ductility increased. Kusumawardaningsih and Hadi [18] studied the effectiveness of FRP confinement on hollow high strength RC columns. Both circular and square columns with either circular or square hollow core were cast and tested under axial concentric loading. The FRP in the

21 hoop direction was also used to wrap specimens in their experiment. It was found that FRP 22 confinement increased the strength and ductility of hollow core high strength RC columns. 23 Hollow core columns having circular holes showed better performance as compared to 24 columns having square holes. 
1 Internally confined hollow (ICH) RC columns were suggested and investigated by Han et

2 al. $[19,20]$. In an ICH RC column, a tube is placed at the inner face of the column to confine

3 the concrete wall element. The test results revealed that the internal confinement existed and

4 made the concrete in the state of triaxial confinement. The internal confinement prevented the

5 spalling of the inner face of the concrete, and increase in the strength of the concrete as a

6 result of in the state of triaxial confinement.

7 There have also been studies on confining the concrete of both outer and inner face of 8 hollow concrete columns in order to make the concrete under triaxial confinement. Hybrid

9 FRP-concrete-steel double-skin tubular columns (referred to as DSTCs) have been introduced 10 Teng et al. [21] for one of such purposes. A hybrid DSTC consists of a layer of concrete 11 sandwiched between an outer tube made of FRP and an inner tube made of steel. Several 12 studies have been carried out on this type of structure [21-26]. These test results confirm that 13 the concrete in the new column is very effectively confined by the two tubes. The FRP tube offers mechanical resistance primarily in the hoop direction to confine the concrete and to enhance the shear resistance of the member; the steel tube acts as the main longitudinal reinforcement and prevents the concrete from inward spalling. However, this type of structure is not of interest to the present study.

From the above review, it is shown that no study has been conducted on the investigation of the behaviour of hollow core columns wrapped with different fibre orientations under various eccentricities.

\section{Experimental program}

\subsection{Specimen preparation}

In order to investigate the effect of ply configuration on the behaviour of hollow core RC 
1 columns confined with FRP, a total of twelve specimens were designed, cast, and tested to

2 failure. All the specimens were made of reinforced concrete with the same amount of internal

3 steel reinforcement and were designed according to the requirements of the Australian

4 Standard AS 3600-2009 [27]. All tests were carried out at the laboratories of the School of

5 Civil, Mining, and Environmental Engineering, University of Wollongong.

6 The specimens had square cross-section with $200 \mathrm{~mm}$ side dimension, $800 \mathrm{~mm}$ height, and 7 a 80x80 mm hole at their center. All corners of the specimens were rounded to $32 \mathrm{~mm}$ radius

8 to prevent premature failure of FRP wraps due to stress concentration. The specimens'

9 dimensions were chosen based on the available equipment. The specimens were considered 10 to be short columns. $60 \mathrm{~mm}$ wall thickness was designed to ensure a clear concrete cover of $1120 \mathrm{~mm}$ was maintained at both outer and hole faces of the column as specified in AS 36002009 [27]. With the wall width-to-thickness ratio of 1.33, which is less than 15, the failure mode of the compression flange will be controlled by crushing of the concrete instead of local buckling [28] . The size effect, however, is not considered in this study. Two types of steel reinforcement were used. 12 mm diameter deformed bars N12 (500 MPa nominal tensile strength) were used for longitudinal reinforcement. 6 mm diameter plain bars R6 (250 MPa nominal tensile strength) were used for transverse reinforcement and were placed at $100 \mathrm{~mm}$ spacing. Details of the dimensions and reinforcement are given in Fig. 1.

For all columns, four strain gages were bonded at mid-height of the four longitudinal steel bars, and two strain gages were bonded on the tie at mid-height of the column. These strain gages were used to check the strain in the steel reinforcement.

A wooden formwork having twelve square holes was used to cast the specimens. To create the inside hole, twelve $80 \mathrm{~mm}$ by $80 \mathrm{~mm}$ wooden boxes were also made and placed at the center of each mold. Four foam arches with $32 \mathrm{~mm}$ radius were placed at the four corners of 
1 each hole to produce round corners for the specimens. $40 \mathrm{MPa}$ nominal compressive strength

2 concrete was used in this experiment and was supplied by a local supplier in one batch of

3 concrete. The concrete had $130 \mathrm{~mm}$ slump ensuring its workability. The concrete was then

4 placed into the formwork at three stages. At each stage, vibration was carried out using two

5 vibrators to ensure compaction of concrete. Cylinders (100 mm diameter and $200 \mathrm{~mm}$ height)

6 were also cast to determine the properties of concrete.

7 After casting, the specimens were cured in their forms in moist conditions. Wet hessian

8 rugs were placed on the top of all the specimens and were watered twice a day to keep them 9 moist. The formwork was removed after 21 days of casting the specimens.

\subsection{Wrapping and curing FRP}

Before wrapping FRP, the concrete surface was prepared carefully. The concrete surface of all specimens was found to be intact after removing the formwork. Therefore, there was no need for repair or patch, except the surface at corners due to using foam. These locations were then ground using a grinder and a steel brush to make them smooth.

Unidirectional CFRP fibre sheets (CARBON-UNI340GM-75MM) were used in this experimental program to wrap the specimens using wet layup system. The nominal width and thickness of the CFRP sheet were $75 \mathrm{~mm}$ and $0.45 \mathrm{~mm}$, respectively. The properties of FRP were determined from the FRP coupon tests according to ASTM D7565 [29]. FRP coupons consisting of one, two and three parallel CFRP layers were prepared and tested. Test results are shown in Table 1. The adhesive was mixed from epoxy resin and slow hardener at a ratio of 5:1 as recommended by the manufacturer.

The twelve specimens were sub-divided into four groups with three specimens each. The specimens of the first group (RC Group) without any FRP wraps served as reference 
1 specimens. The specimens of the second group (HF Group) were laterally wrapped with three

2 CFRP layers with respect to the specimen's axial axis. The specimens of the third group

3 (VHF Group) were vertically wrapped with one CFRP layer along the specimen's axial axis,

4 and then horizontally wrapped with two CFRP layers. All the specimens of the last group

5 (AHF Group) were wrapped with two CFRP layers oriented at $\pm 45^{0}$ with respect to

6 specimen's axial axis, and then horizontally wrapped with one layer of CFRP.

7 The wrapping procedure was done as follows. The surface of the specimens was coated

8 with a thin layer of epoxy resin first, and then the first layer of CRRP was applied at the

9 design orientation. The first layer of FRP was then coated with epoxy again before the 10 application of the second FRP layer. The process was repeated until all the design FRP layers were applied. An overlap of $100 \mathrm{~mm}$ was made in the last revolution and was applied only in the hoop direction. Two extra lateral FRP layers and 75 mm length vertical FRP layers were applied at the ends of all specimens in order to protect the two ends against premature failure 14 due to stress concentration and from early cracking on the tension sides of the ends under 15 eccentric loading. After completing wrapping, all specimens were left for at least 14 days for binder curing.

\subsection{Preliminary testing}

Preliminary testing included testing concrete cylinders, reinforcing bars. Determination of concrete properties was conducted according to the Australian Standards AS 1012.8 [30] and AS 1012.9 [31] for concrete cylinders. The cylinder dimensions were $100 \mathrm{~mm}$ diameter and $200 \mathrm{~mm}$ height. The average 28 day concrete compressive strength was $38 \mathrm{MPa}$. The tensile 22 testing method according to Australian Standard AS 1391 [32] was used to determine the 23 reinforcing steel properties. The average tensile strength and tensile strain of N12 were 587 MPa and 0.0029, respectively. Those for R6 were $538 \mathrm{MPa}$ and 0.00269, respectively. 
1

\subsection{Testing specimens}

2 Testing of the specimens was conducted at the High Bay laboratory, University of

3 Wollongong using the Dension $5000 \mathrm{kN}$ compression testing machine. From each group, the

4 specimens were tested as columns at eccentricities of 0 (concentric), $25 \mathrm{~mm}$ and $50 \mathrm{~mm}$.

5 These specimens were denoted by the group label accompanied with 0, 25 and 50 at the end.

6 For example, Specimens RC-0, RC-25, RC-50 denote that these specimens are in Group RC

7 (reference columns) and were tested under an eccentricity of 0, 25, and $50 \mathrm{~mm}$, respectively.

8 The test matrix is given in Table 2.

9 Square, steel loading caps were used in testing all specimens (Fig. 2). The loading cap consists of two parts: a $50 \mathrm{~mm}$ thick steel plate, called adaptor plate, which exerts the load to

11 the column, and a $25 \mathrm{~mm}$ thick steel plate with a circular roll joint, which was only used in 12 eccentric loading tests that ensure rotation capacity of column's ends during test. As such, the boundary condition of the eccentrically loaded columns was pin-pin (refer to Fig. 3). Details

14 of the loading caps are described in Hadi and Widiarsa [6]. High strength plaster was placed in the caps (to create a level surface between the plate and the bottom or top ends of the specimens) and left to set for at least 45 mins before testing. The bottom loading cap was 17 cantered using a rig holding the column in place. A forklift was used to place the specimen in the testing machine. The top loading cap was placed as the column was lifted into place. A photo of a typical compression testing is shown in Fig. 4.

In order to measure the lateral displacement of the columns, a laser triangulation sensor was placed horizontally at the front of the protective perspex shield with a small cutout hole for the sensor. A data taker was used to link the testing machine with a computer to detect the loading ram that exerts the load, the longitudinal deflection, and the lateral deflection from the laser triangulation sensor. Testing commenced under displacement controlled condition. 
1 All tests were conducted at a rate of $0.3 \mathrm{~mm} / \mathrm{min}$.

\section{Results and discussions}

3 Table 3 shows results of testing all columns. The ultimate displacement was taken at the

4 point when the corresponding axial load was equal to $85 \%$ of the maximum load for

5 unwrapped specimens and at the point when the FRP ruptured for confined specimens.

6 Similar to solid reinforced concrete columns, externally wrapping CFRP can increase the

7 performance of hollow core RC columns, in terms of strength and ductility. The gain in

8 strength is significant for columns wrapped exclusively with hoop FRP layers (HF columns)

9 under concentric loading or when the eccentricity of the load is small (25 mm). When the

10 eccentricity is large (50 mm), the strength gain is more considerable for columns with the

11 presence of vertical or $\pm 45^{\circ}$ CFRP wraps (VHF and AHF columns). In addition, hoop orientation wrapping of HF columns increased their ductility significantly compared with unwrapped columns, and columns in Groups VHF and AHF.

\subsection{Behaviour of unwrapped specimens}

The unconfined columns (Group RC) showed the highest load carrying capacity when tested under concentric loading. When eccentricities were introduced, the maximum load carrying capacity decreased significantly due to bending moment effect. These columns did not suffer any large strain after reaching the maximum load. In fact, they failed in a brittle manner characterized by peeling off the concrete and outward buckling of the steel bars within two adjacent ties in the compression side for all columns. Horizontal cracks were formed in the tension side at the failure position of the columns tested under eccentric testing.

\subsection{Behaviour of specimens of the HF group}

Wrapping columns with three layers in the hoop direction was the most efficient method 
1 for increasing the strength and ductility of columns for both concentric and eccentric loading.

2 Specimen HF-0 showed $11 \%$ increase in maximum load compared to the reference specimen

3 RC-0 in concentric testing. Specimens HF-25 and HF-50 achieved 25\% and 9\% increases,

4 respectively compared with the corresponding reference specimens. Specimen HF-0 was

5 expected to gain the highest applied load of the four columns tested concentrically, however a

6 premature failure was observed. After examining the tested HF-0 specimen carefully, it was

7 found that the concrete had spalled at a corner at the surface of the top end where the

8 longitudinal steel bar was exposed. It is to be noted that one longitudinal steel bar was

9 moving upward during casting this specimen. This movement may be the reason for this

10 exposure. Therefore, the concrete cover at the top of this longitudinal steel bar was just $4 \mathrm{~mm}$

11 instead of the required $20 \mathrm{~mm}$. This occurrence caused high stress concentration, resulting in

12 premature damage at the top end of the column at this corner.

In terms of ductility, Figures 5 to 7 show clearly that hoop layers can substantially extend axial displacement as well as lateral displacement of the columns under concentric and eccentric loading. Table 4 shows the ductility calculation for all specimens. In this study ductility was calculated based on axial displacement behaviour which was suggested by GangaRao et al. [33], i.e. the ductility is equal to the ratio of the axial displacement at $85 \%$ maximum load (post-yielding point) $\Delta_{85 \% \text { Pmax }}$ and the axial displacement at yield load $\Delta_{y}$. Hoop orientation wrapping of Specimen HF-0 increased the axial displacement 4.7 times that of the reference specimen RC-0, and around 2.4 times those of Specimens VHF-0 and AHF0. Under eccentric loading, these comparisons are even larger. Specimen HF-50 showed a ductility 7.4 times larger than Specimen RC-50 and about 3.4 times larger than Specimens VHF-50 and AHF-50. The ductility of Specimen HF-25 was not calculated due to an accident that occurred with the machine as testing commenced. The applied load suddenly increased with a very high speed rate and in about 16 seconds, $1250 \mathrm{kN}$ force was applied before the 
1 test was stopped. The load data recorded from the computer showed that the applied load

2 reached the maximum value and then started decreasing. It was decided to start the test again,

3 but some cracks were already found on the FRP layers. The maximum load the column

4 achieved was only about $80 \%$ of the previous value recorded during the accident. The axial

5 and lateral displacements however, were still very large as shown in Fig. 5. Therefore, CFRP

6 layers in the hoop direction were efficient in delaying premature failure of the columns due to

7 the spalling of concrete and buckling of steel bars at yield load.

8 It is worthy to note that when eccentricity was large, the gain in strength of HF columns

9 decreased, whereas the gain in ductility increased. This result is due to FRP in this wrapping 10 method only working in the hoop direction and there is no effect in preventing the loss of 11 strength caused by bending moment.

12 Specimens of Group HF failed in a sudden, dangerous manner. When the applied load increased to large enough values, small cracking sounds were heard. After the maximum and HF-50 was determined to be about $160 \mathrm{~mm} \mathrm{-} 200 \mathrm{~mm}$ from the top end and that for Specimen HF-25 was near the mid-height of the column. All of these FRP layers ruptured at

\subsection{Behaviour of specimens of the VHF and AHF groups}

The behaviours of VHF and AHF columns were quite similar in both concentric and eccentric loading, especially with regards to ductility. Both of these wrapping schemes 
1 improved slightly the ductility of the columns. The combination of two $\pm 45^{\circ}$ oriented CFRP

2 layers and one hoop CFRP layer of AHF columns were expected to show the largest ductility

3 compared to the other schemes, but their gain in ductility was only around 1.6 to 2.1 times

4 larger than the corresponding reference specimens. These results are similar to those of

5 Sadeghian et al. [12] which were conducted on solid plain concrete cylinders. The

6 combination of transverse and angle oriented layers is not effective in enhancing the ductility

7 and energy absorption. Meanwhile, Sadeghian et al. [12] confirmed the significant increase in

8 ductility for cylinders wrapped with only $\pm 45^{\circ}$ orientations.

9 With respect to strength, as expected, the gain in strength of these specimens increased the columns were tested concentrically, there was no contribution of vertical and angle layers resulting in only a slight increase in the strength, which in fact came from the hoop layers (Table 3). At an eccentricity of $50 \mathrm{~mm}$, the contribution of vertical and angle layers became clearer. The increase in strength of Specimens VHF-50 and AHF-50 were even greater than that of Specimen HF-50 (i.e. 9\% for HF-50, meanwhile 18\% and 14\% for VHF-50 and AHF50, respectively). Therefore, the presence of vertical and angle CFRP orientation is clearly efficient in resisting bending moments due to eccentricities, which results in premature failure of RC columns. This achievement is similar to Hadi [5] and Hadi and Widiarsa [6] in testing solid reinforced concrete columns when vertical FRP layers were added.

Specimens in Groups VHF and AHF also failed in a sudden and explosive manner. When the applied load was large enough, small cracking sounds were heard. A bulging deformation on the outer hoop FRP layer in the compression side was also observed. After the maximum load, the load carrying capacity of VHF and AHF specimens reduced significantly. The rupture of the outer hoop layers caused a loud explosive noise and the load dropped. 
1 All VHF columns failed at a position approximately $130 \mathrm{~mm}$ from the top end. With the

2 exception of Specimen VHF-0, the rupture of FRP in VHF specimens (VHF-25 and VHF-50)

3 occurred in the middle, on the side of the column, not at the corner. After examining inside

4 the hole of these specimens, it was found that the concrete at the inner corners broke in a way

5 that tends to make the cross-section of the hole at failure position circular, as a result, the

6 concrete in the middle of the compression side expanded outwards causing the FRP failure

7 near the middle side of the column.

8 For AHF columns, the rupture of FRP started from the corner and further developed into 9 an approximate $45^{\circ}$ downward angle in the compression side of the column. The failure 10 positions varied between $130 \mathrm{~mm}$ to $200 \mathrm{~mm}$ from the bottom end of the columns.

11 All the specimens failed near the ends, not the desired midspan. Possible reason is the 12 stress concentration at the boundaries.

\section{4. Theoretical considerations}

14 In order to predict the axial loading capacity and combined axial compression and flexure, 15 P-M interaction diagrams were drawn based on theoretical calculations for both unconfined 16 RC columns and FRP-confined columns.

17 For unconfined RC columns, P-M diagrams can be developed by satisfying strain 18 compatibility and force equilibrium using the model for the stress-strain behaviour of 19 conventional RC columns. The detailed procedure is based on Warner et al. [34].

A similar procedure was applied to construct the P-M diagram for FRP-confined 21 specimens. However, the stress-strain model for unconfined concrete was replaced by a 22 stress-strain model for FRP-confined concrete. When observing the load-axial displacement 
1 response diagrams, it is noted that all of FRP-confined specimens exhibited stress-strain

2 curves of descending type. In these curves, the maximum confined concrete strength $f_{c c}$ ' was

3 greater than the unconfined concrete strength $f^{\prime}{ }_{c o}$. The axial strength of confined concrete at

4 ultimate axial strain $f_{c u}^{\prime}$ fell below $f^{\prime}$ co. These curve types are similar to the stress-strain

5 curves originally developed by Mander et al. [35] for steel confined concrete which was

6 adopted by ACI 440.2R-02 [36] with modifications for FRP-confined concrete. ACI 440.2R-

708 [37] adopted the stress-strain model proposed by Lam and Teng [38] for FRP-confined

8 concrete. However, this model is only applicable for a nondescending second branch in the

9 stress-strain performance, in which, the maximum value of $f^{\prime}{ }_{c c}$ is reached at the same time 10 with the ultimate strain of FRP (the failure strain of FRP) $\varepsilon_{\text {сси. }}$ To assure an ascending second 11 branch of the stress-strain curve a minimum level of confinement is required, i.e the ratio $f_{l}$ 12 / $f^{\prime}{ }_{c}$ should not be less than 0.08 [37] or 0.07 [38], below which the FRP is considered to result 13 in no enhancement in the compressive strength of concrete, i.e $f^{\prime}{ }_{c c} / f^{\prime}{ }_{c o}=1$ if $f_{l} / f^{\prime}{ }_{c}<0.07$, as 14 suggested by Lam and Teng [38]. In the present study, the maximum confined concrete 15 strength $f^{\prime}{ }_{c c}$ was higher $f^{\prime}{ }_{c o}$ and was reached before the failure strain of FRP $\varepsilon_{c c u}$. Since there 16 is no specific stress-strain model for FRP-confined hollow core rectangular columns at the 17 present time, the approach presented in ACI 440.2R-02 [36] for solid sections was used 18 herein to calculate compressive strength enhancement. The achieved results show good 19 agreement with the results obtained from the experiments.

20 The maximum confined concrete strength $f_{c c}^{\prime}$ and the corresponding strain $\varepsilon_{c c}^{\prime}$ were 21 computed by using Eqs.1 and 2, respectively:

$$
f_{c c}^{\prime}=f_{c}^{\prime}\left[2.25 \sqrt{1+7.9 \frac{f_{l}}{f_{c}^{\prime}}}-2 \frac{f_{l}}{f_{c}^{\prime}}-1.25\right]
$$


2 Where, $f_{c}^{\prime}$ is the unconfined concrete strength, $E_{c}$ is the modulus of elasticity of unconfined

3 concrete, $f_{l}$ is the confining pressure given in Eq. 3:

4

$$
f_{l}=\frac{\kappa_{a} \rho_{f} f_{f e}}{2}=\frac{\kappa_{a} \rho_{f} \varepsilon_{f e} E_{f}}{2}
$$

5 Where, $\kappa_{a}$ is a shape factor, and $\rho_{f}$ is a reinforcement ratio, which were computed by using 6 Eqs. 4 and 5 for non-circular sections, respectively. $f_{f e}$ is the effective stress in FRP attained 7 from tensile modulus of elasticity of FRP $E_{f}$, and effective strain in FRP $\varepsilon_{f e}$ at failure section.

8 The efficiency of the FRP jacket is directly related to the strain efficiency factor $\kappa_{\varepsilon}$. This 9 factor accounts for the difference between the actual tensile strain at rupture of FRP jacket $\varepsilon_{f e}$ 10 and the ultimate strain reported from flat coupon tests $\varepsilon_{f u}$. Carey and Harries [39] reported 11 strain efficiency factor values of 0.13 and 0.16 for one medium-scale and one large-scale 12 CFRP- wrapped square RC columns. Toutanji et al. [40] reported values of 0.16 and 0.26 for 13 two large-scale square RC columns. The value of 0.16 was used in the calculations in this 14 paper.

$$
\begin{aligned}
\rho_{f} & =\frac{2 n t_{f}(b+h)}{A_{\text {net }}} \\
\kappa_{a} & =1-\frac{(b-2 r)^{2}+(h-2 r)^{2}}{3 A_{\text {net }}\left(1-\rho_{g}\right)}
\end{aligned}
$$

17 where $n$ is the number of FRP layers, $t_{f}$ is the thickness of one FRP layer, $b$ and $h$ are the 18 dimensions of the section, $r$ is the radius of corners of the section, $\rho_{g}$ is the cross sectional 19 area ratio of the longitudinal steel reinforcement. Note that for Eqs. 4 and 5, the section gross area $A_{g}$ was replaced by the net area of the hollow section, i.e $A_{\text {net }}=A_{g}-A_{\text {hollow }}$, where $A_{\text {hollow }}$ 
1 is the area of the hollow part. Eq. 5 was applicable for square sections because the ratio of $b$

2 and $h$ equal to 1 , the size effect was not considered.

3 The axial load capacity under concentric loading was computed by using Eq. 6:

4

5 where, $f_{y}, A_{s}$ are the yield strength and area of longitudinal steel reinforcement, respectively.

6 For columns with the presence of vertical or $\pm 45^{\circ}$ oriented layers it was assumed that there is

7 no contribution of these layers in concrete core confinement under concentric loading. These

8 contributions were only taken into account in case of eccentric loading, where combined axial

9 compression and flexure took place. The axial load capacity $N_{u}$ and bending moment $M_{u}$ were 10 computed by using Eqs. 7 and 8:

$$
\begin{gathered}
N_{u}=\left(C_{c}+C_{s}\right)-\left(T+T_{f r p}\right) \\
M_{u}=C_{c}\left(d_{P C}-Y_{c}\right)+S_{c}\left(d_{P C}-d_{s c}\right)+T\left(d-d_{P C}\right)+T_{f r p}\left(d_{f r p}-d_{P C}\right)
\end{gathered}
$$

where, $C_{c}, C_{s}$ are the compressive forces in concrete and longitudinal steel reinforcement, respectively. $T$, $T_{\text {frp }}$ are tensile forces in the tensile steel reinforcement and FRP, respectively. $d_{P C}, d_{s c}, d, d_{f r p}$ are distances from the extreme compression concrete fibre to the plastic centroid, centroids of compressive steel reinforcement, tensile steel reinforcement and FRP, respectively; and $Y_{c}$ is the centroid of concrete in the compression region. Rectangular stress block was used to compute the compressive concrete stress $f_{c c}^{\prime}$ because at the point where the strain in tensile steel reinforcement is equal to zero the neutral axis depth $d_{n}$ at failure is at the level of the tensile reinforcement. Also, at the balanced failure condition, the neutral axis depth $d_{n}$ was also noticed to be very close to the flanges that do not contain a large hollow part. 
The strain in FRP $\varepsilon_{f r p}$ was computed using strain compatibility, which was controlled by

2 both confined concrete axial strain $\varepsilon_{c c}$ at maximum stress $f_{c c}^{\prime}$, and effectively hoop rupture

3 strain of FRP $\varepsilon_{f e}$.

$$
\varepsilon_{f r p}=\varepsilon_{c c}\left(\frac{d_{f r p}-d_{n}}{d_{n}}\right) \leq \varepsilon_{f e}
$$

5 In which, $d_{f r p}$ is the distance from the extreme compression fibre to the neutral axis, taken

6 equal to the cross-section depth $h$.

7 The theoretical calculation results are given in Table 5. Fig. 9 shows the theoretical P-M 8 interaction diagrams of all groups of specimens. It can be seen that with the assumption of no 9 contribution of vertical or angle oriented FRP layers under concentric loading, the gain in 10 strength of columns depend on the thickness of hoop FRP layers. The increase in the number 11 of hoop FRP layers can result in an increase in the compression strength capacity of the 12 columns subjected to concentric loads. The test results were of the same tendency (refer to 13 Table 3). The theoretical pure bending moments of RC specimens and HF specimens were 14 15 16 to the tensile steel reinforcement.

Figures 10 - 13 show comparisons of the P-M interaction diagrams between the theoretical calculation and the experimental results for the four groups of specimens.

For $25 \mathrm{~mm}$ and $50 \mathrm{~mm}$ eccentrically loaded specimens, bending moment capacities $\left(M_{I}\right)$ 20 were calculated by multiplying the maximum axial load capacity $\left(P_{\max }\right)$ and the 21 corresponding eccentricity (e). Secondary bending moments $\left(M_{I I}\right)$ were also calculated as 22 follows:

$$
M_{I I}=P_{\max }(e+\delta)
$$


1 where $\delta$ is the corresponding lateral deflection at the maximum load $P_{\max }$.

2 From Figures $10-13$, it can be seen that the theoretical calculations were in good

3 agreement with the experimental results. With the exception of Specimens HF-0 and HF-50,

4 the theoretical results underestimated the experimental results for all of the specimens. For

5 unwrapped specimens there were about $2 \%$ to $5 \%$ differences between the theoretical and the

6 experimental results. VHF specimens and AHF specimens showed differences of $5.0 \%$ to

$7 \quad 10.5 \%$ and $3.8 \%$ to $8.4 \%$, respectively. Specimen HF-0, which got premature failure during

8 concentric testing process showed $-3.2 \%$ difference from the theoretical prediction and that

9 for Specimen HF-50 was $-7.3 \%$ (the minus sign here denotes the experimental results were 10 lower than the calculated results). Specimen HF-25 showed 10\% difference compared with 11 theoretical calculation.

12 The theoretical strain results of reinforcement were also compared with the data obtained 13 from strain gages showing good predications. Two types of strain gages were used: PFL-1014 11-1LJB (10 mm length, 2\% limit strain) was used for longitudinal steel bars, FLA-11-1L (5 $15 \mathrm{~mm}$ length, $1 \%$ limit strain) for ties. Details of arrangement of strain gages are given in Fig. 1614.

17 Table 6 shows the strain of longitudinal steel bars from strain gages and compared with 18 the theoretical calculations at maximum load for all of the specimens under concentric 19 loading, $25 \mathrm{~mm}$ and 50 eccentricities. For concentric loading, the theoretical strain of steel 20 bars was assumed to have yielded and equal to $2900 \mu \varepsilon$. The experimental strain was taken 21 by the average value of four strain gages glued on the four longitudinal steel bars. The strain 22 of Specimen RC-0 showed $8.8 \%$ difference compared to the theoretical calculation, 23 meanwhile Specimens VHF-0 and AHF-0 were $14 \%$ and $15.4 \%$, respectively. The 
1 longitudinal steel bars strain of Specimen HF-0 was not applicable here because of the

2 variation due to premature failure.

3 In case of eccentric loading, the theoretical strains of longitudinal steel bars were carried

4 out for the steel bars on the tension side and compression side based on the principles of

5 strain compatibility and were controlled by concrete strain at maximum load $\varepsilon_{c c}$ and the

6 effective strain in FRP $\varepsilon_{f e}$. The strains in the steel bars on the compression side of unwrapped

7 Specimens RC-25 and RC-50 showed about 27\% difference compared to theoretical

8 calculation, while those differences for Specimens HF and VHF were between 12\% and 20\%.

9 Specimens AHF-25 and AHF-50 showed differences of 32\% and 27.2\%, respectively. The 10 strain in the steel bars on the tension side showed very good agreement with the theoretical 11 calculations for $50 \mathrm{~mm}$ eccentric loading. At this eccentricity, the theoretical strain of the tensile steel layer is equal to zero. For $25 \mathrm{~mm}$ eccentric loading, the strain in the tensile steel bars showed large differences compared to the theoretical calculations. These strain values in fact were very small, which may have been caused by inaccuracy.

The strain in ties in both tension and compression sides were also measured and are given in Table 7. It is to be noted that in cases of concentric loading or when the eccentricity was small $(25 \mathrm{~mm})$, the strain in the ties of all the specimens was significant at maximum load, but the ties had not yielded yet. Therefore, it is necessary to take the contribution of ties into account in calculating the strength of confined concrete in the cases where the stress-strain curves are of the descending types and the ties have been still working. When the eccentricity was large $(50 \mathrm{~mm})$, the strain of ties decreased considerably. The fact that up to the yield point of the steel, no differences exist in the confinement mechanism between steel and FRP as they both behave in a linear elastic way. This may explain the inefficiency of FRP under large eccentric loading where the premature failure due to bending moment dominates the 
1 failure modes of the specimens. In addition, at the tension side when the strain of longitudinal

2 steel bars were close to zero, the strain of tie at that side was also close to zero.

\section{5. Conclusions}

4 In order to investigate the effect of fibre orientation on hollow core square reinforced

5 concrete columns confined with Carbon fibre-reinforced polymer, three orientations of fibre

6 wrapping were used and tested on twelve specimens under both concentric and eccentric

7 conditions. From the test results, the following conclusions are drawn:

8 The fibre in the hoop direction can significantly increase the ductility of hollow core 9 square reinforced concrete columns under concentric or eccentric loading. Compared to VHF 10 and AHF columns, HF columns can sustain much larger deformation before failure. 11 However, the increment of the compressive strength of FRP-confined hollow core columns is 12 marginal.

13 When columns were tested under eccentric loading, the contribution of vertical and $\pm 45^{\circ}$ angle layers was evident in resisting the bending moment. This contribution was more noticeable as the eccentricity increased. In fact, Specimens AHF-50 and VHF-50, which were wrapped with one and two hoop CFRP layers gained maximum axial load even greater than 17 that of Specimen HF-50, which was wrapped with three CFRP layers in the hoop direction. 18 There is no contribution of these vertical and angle wraps on the strength of columns under 19 concentric loads.

In this paper, the combination of $\pm 45^{\circ}$ oriented CFRP layers and one hoop layer did not 21 show any significant increase in deflections of the columns under both concentric and 22 eccentric testing. Possible reason is that the contribution of axial loading is more than that of 23 bending in this experiment. 
1 Although Mander et al.'s stress-strain model (1988) is for solid rectangular RC columns,

2 the theoretical calculations using this model for predicting the strength of the tested

3 specimens were in good agreement with the experimental results. The selection of Mander et

4 al.'s model (1988) in this paper was based on the shape of the stress-strain curves of the

5 tested specimens. In the authors' opinion, when a column shows a stress-strain curve of

6 ascending type, which is similar to that of Mander et al.'s model (1988), the behaviour of that

7 column is similar to specimens studied by Mander et al. (1988).

8 Finally, all of the three wrapping combinations used in this study increased the 9 performance of hollow core square columns. The enhancement in ductility was more evident 10 than the enhancement in strength for all types of wrapping, in particular for columns wrapped 11 with only hoop-oriented layers.

\section{Acknowledgement}

13 The authors would like to thank staff at the High Bay laboratory, University of Wollongong, 14 especially Mr. Fernando Escribano for their technical help during the experimental program. 15 Thanks are expressed to PhD scholar Mr. Ida Bagus Rai Widiarsa for his design of loading 16 heads, which used in this experiment. Finally, the second author would like to acknowledge

17 Hong Duc, Thanh Hoa, Vietnam and UOW Research Scholarship Program for the support of 18 his full Masters scholarship. 
1

\section{References}

2 [1] Li J, Hadi MNS. Behaviour of externally confined high-strength concrete columns under eccentric loading. Composite Structures 2003;62(2):145-153.

[2] Hadi MNS. Comparative study of eccentrically loaded FRP wrapped columns. Composite Structures 2006;74(2):127-135.

6 [3] Hadi MNS. Behaviour of FRP wrapped normal strength concrete columns unde

8 [4] Fitzwilliam J, Bisby L. Slenderness effects on circular CFRP confined reinforced concrete columns. Journal of Composites for Construction 2010;14(3):280-288.

[6] Hadi MNS, Widiarsa IBR. Axial and Flexural Performance of Square RC Columns Wrapped with CFRP under Eccentric Loading Journal of Composites for Construction 2012;16(6):640-649.

[7] Tan KH. Strength enhancement of rectangular reinforced concrete columns using fibre-reinforced polymer. Composites in Construction 2002;6(3):175-183.

[8] Rochette P, Labossiere P. Axial testing of rectangular column models confined with composites. Journal of Composites for Construction 2000;4(3):129-136.

[9] Mirmiran A, Shahawy M. Behaviour of concrete columns confined by fibre composites. Journal of structural engineering New York, N.Y. 1997;123(5):583-590.

[10] Pessiki S, Harries KA, Kestner JT, Sause R, Ricles JM. Axial behaviour of reinforced concrete columns confined with FRP jackets. Journal of Composites for Construction 2001;5(4):237-245.

[11] Li G, Maricherla D, Singh K, Pang S-S, John M. Effect of fibre orientation on the structural behaviour of FRP wrapped concrete cylinders. Composite Structures 2006;74(4):475-483.

[12] Sadeghian P, Rahai AR, Ehsani MR. Effect of Fibre Orientation on Compressive Behaviour of CFRP-confined Concrete Columns. Journal of Reinforced Plastics and Composites 2010;29(9):1335-1346.

[13] Parvin A, Jamwal AS. Effects of wrap thickness and ply configuration on compositeconfined concrete cylinders. Composite Structures 2004;67 (2005):437-442. 
1 [14] Parvin A, Jamwal AS. Performance of externally FRP reinforced columns for changes in angle and thickness of the wrap and concrete strength. Composite Structures 2005;73 (2006):451-457.

[15] Hajsadeghi M, Alaee FJ, Shahmohammadi A. Investigation on Behaviour of Square/Rectangular Reinforced Concrete Columns Retrofitted with FRP Jacket. Journal of Civil Engineering and Management 2011;17(3):400-408.

[16] Lignola GP, Prota A, Manfredi G, Cosenza E. Experimental performance of RC hollow columns confined with CFRP. Journal of Composites for Construction 2007;11(1):42-49.

[17] Yazici V, Hadi MNS. Axial load-bending moment diagrams of carbon FRP wrapped hollow core reinforced concrete columns. Journal of Composites for Construction 2009;13(4):262-268.

[18] Kusumawardaningsih Y, Hadi MNS. Comparative behaviour of hollow columns confined with FRP composites. Composite Structures 2010;93(1):198-205.

[19] Han TH, Stallings JM, Cho SK, Kang YJ. Behaviour of a hollow RC column with an internal tube. Magazine of Concrete Research 2010;62(1):25-38.

[20] Han TH, Yoon KY, Kang YJ. Compressive strength of circular hollow reinforced concrete confined by an internal steel tube. Construction and Building Materials 2010;24(9):1690-1699.

[21] Teng JG, Yu T, Wong YL, Dong SL. Hybrid FRP-concrete-steel tubular columns: Concept and behaviour. Construction and Building Materials 2007;21(4):846-854.

[22] Wong YL, Yu T, Teng JG, Dong SL. Behaviour of FRP-confined concrete in annular section columns. Composites Part B: Engineering 2008;39(3):451-466.

[23] Xie P, Yu T, Wong YL, Teng JG. Compressive behaviour of large-scale hybrid FRPconcrete-steel double-skin tubular columns. in 1st International Conference on Civil Engineering, Architecture and Building Materials, CEABM 2011, June 18, 2011 June 20, 2011. 2011. Haikou, China: Trans Tech Publications.

[24] Yu T, Teng JG. Behaviour of hybrid FRP-concrete-steel double-skin tubular columns with a square outer tube and a circular inner tube subjected to axial compression. Journal of Composites for Construction 2013;17(2):271-279.

[25] Yu T, Teng JG, Wong YL. Stress-strain behaviour of concrete in hybrid frp-concretesteel double-skin tubular columns. Journal of Structural Engineering 2010;136(4):379-389. 
1 [26] Yu T, Wong YL, Teng JG. Behaviour of hybrid FRP-concrete-steel double-skin tubular columns subjected to eccentric compression. Advances in Structural Engineering 2010;13(5):961-974.

[27] AS 3600-2009. Concrete structure. Standards Australia Limited, NSW 2009.

5 [28] Taylor AW, Rowell RB, Breen JE. Behaviour of thin-walled concrete box piers. ACI Structural Journal 1995;92(3):319-333.

[29] ASTM D7565/D7565M - 10. Standard Test Method for Determining Tensile Properties of Fibre Reinforced Polymer Matrix Composites Used for Strengthening of Civil Structures. ASTM International, United States 2010.

[30] AS 1012.8-2000. Methods of testing concrete. Standards Australia International Ltd., NSW 2000.

[31] AS 1012.9-1999. Methods of testing concrete. Standards Australia International Ltd., NSW 1999.

[32] AS 1391-2007. Metallic materials - Tensile testing at ambient temperature. Standards Australia Limited, NSW 2007.

[33] GangaRao HVS, Taly N, Vijay PV, Reinforced concrete design with FRP composites. 2007: New York : CRC ; London : Taylor \& Francis.

[34] Warner RF, Foster SJ, Kilpatrick AE. Reinforced concrete basics : analysis and design of reinforced concrete Pearson Prentice Hall, Frenchs Forest, N.S.W 2007.

[35] Mander JB, Priestley MJN, Park R. Theoretical stress-strain model for confined concrete. Journal of structural engineering New York, N.Y. 1988;114(8):1804-1826.

[36] ACI 440.2R. Guide for the Design and Construction of Externally Bonded FRP Systems for Strengthening Concrete Structures. American Concrete Institute, Farmington Hills, USA 2002.

[37] ACI 440.2R. Guide for the Design and Construction of Externally Bonded FRP Systems for Strengthening Concrete Structures. American Concrete Institute, Farmington Hills, USA 2008.

[38] Lam L, Teng JG. Design-oriented stress-strain model for FRP-confined concrete in rectangular columns. Journal of Reinforced Plastics and Composites 2003;22(13):1149-1186.

[39] Carey S, Harries K. The Effects of Shape, 'Gap', and Scale on the Behaviour and Modeling of Variably Confined Concrete. Report No. ST03-05, University of South Carolina, Columbia, SC 2003. 
1 [40] Toutanji H, Han M, Gilbert J, Matthys S. Behaviour of large-scale rectangular columns confined with FRP composites. Journal of Composites for Construction 3 2010;14(1):62-71. 


\section{$1 \quad$ List of Figures}

2 Fig. 1. Details of test specimens and reinforcement

3 Fig. 2. A photo of loading caps

$4 \quad$ Fig. 3. Eccentric loading mechanism

$5 \quad$ Fig. 4. Test set up

6 Fig. 5. Load-axial displacement curves for concentrically loaded columns

7 Fig. 6. Load-displacement curves for 25 mm eccentrically loaded columns. Note: HF-25 (1)

8 and HF-25 (2) refer to 1st and 2nd loading periods of Specimen HF-25 due to an accident

9 during test.

10 Fig. 7. Load-displacement curves for $50 \mathrm{~mm}$ eccentrically loaded columns

11 Fig. 8. Failure modes of all specimens

12 Fig. 9. Theoretical calculation of P-M interaction diagrams

13 Fig. 10. Theoretical and experimental P-M interaction diagrams for columns in Group RC

14 Fig. 11. Theoretical and experimental P-M interaction diagrams for columns in Group HF

15 Fig. 12. Theoretical and experimental P-M interaction diagrams for columns in Group VHF

16 Fig. 13. Theoretical and experimental P-M interaction diagrams for columns in Group AHF

17 Fig. 14. Location of strain gages at mid-height of the column 
1 List of es

1

2

3

4

5

2 Table 1. FRP coupon test results

3 Table 2. Configuration of specimens

$4 \quad$ Table 3. Summary of testing results

5 Table 4. Calculation of ductility

6 Table 5. Summary of theoretical calculations

7 Table 6. Theoretical and experimental strains of longitudinal steel bars at maximum load

8 Table 7. Strain of the tie at mid-height for all of specimens 
Table 1

FRP coupon test results

\begin{tabular}{|c|c|c|c|}
\hline Configuration & 1 layer & 2 layers & 3 layers \\
\hline Width, mm & 23.9 & 24.7 & 25.3 \\
\hline Gage length, mm & 138 & 138 & 138 \\
\hline Maximum tensile force & & & \\
\hline $\begin{array}{l}\text { before failure, } \mathrm{N} \\
\text { Maximum }\end{array}$ & 13785 & 25891 & 38370 \\
\hline $\begin{array}{l}\text { displacement, mm } \\
\text { Maximum tensile force }\end{array}$ & 2.058 & 2.075 & 2.398 \\
\hline per unit width, N/mm & 1165.3 & 1150.7 & 1136.9 \\
\hline Maximum strain & 0.0149 & 0.0185 & 0.0174 \\
\hline $\begin{array}{l}\text { Tensile modulus of } \\
\text { elasticity, } \mathrm{MPa}\end{array}$ & 78080 & 76503 & 65310 \\
\hline
\end{tabular}


Table 2

Configuration of specimens

\begin{tabular}{llll}
\hline Specimen $^{1}$ & $\begin{array}{l}\text { Internal } \\
\text { reinf. }\end{array}$ & $\begin{array}{l}\text { Configuration } \\
\text { CFRP }\end{array}$ & $\begin{array}{l}\text { Eccentricity } \\
\mathrm{mm}\end{array}$ \\
\hline RC-0 & & & 0 \\
RC-25 & Yes & None & 25 \\
RC-50 & & & 50 \\
\hline HF-0 & & Three & 0 \\
HF-25 & Yes & hoop & 25 \\
HF-50 & & layers & 50 \\
\hline VHF-0 & & One vertical & 0 \\
VHF-25 & Yes & and two hoop & 25 \\
VHF-50 & & layers & 50 \\
\hline AHF-0 & & Two $\left( \pm 45^{0}\right)$ & 0 \\
AHF-25 & Yes & and one hoop & 25 \\
AHF-50 & & layers & 50 \\
\hline
\end{tabular}

${ }^{1}$ All specimens have the dimensions 200x200 mm in cross-section and $800 \mathrm{~mm}$ in height. 
Table 3

Summary of testing results

\begin{tabular}{|c|c|c|c|c|c|c|c|}
\hline \multirow[t]{3}{*}{ Specimen } & \multirow[t]{2}{*}{$\begin{array}{l}\text { Max. } \\
\text { load }\end{array}$} & \multicolumn{2}{|c|}{$\begin{array}{l}\text { Corresponding } \\
\text { displacement at } \\
\text { max. load }\end{array}$} & \multicolumn{2}{|c|}{$\begin{array}{l}\text { Ultimate } \\
\text { displacement }\end{array}$} & \multirow{3}{*}{$\begin{array}{l}\text { Corr. axial load } \\
\text { at ultimate } \\
\text { displacement } \\
\qquad \mathrm{kN}\end{array}$} & \multirow[t]{3}{*}{$\begin{array}{l}\text { Normalize } \\
\text { d max. } \\
\text { load }\end{array}$} \\
\hline & & Axial & Lateral & Axial & Lateral & & \\
\hline & kN & $\mathrm{mm}$ & $\mathrm{mm}$ & $\mathrm{mm}$ & $\mathrm{mm}$ & & \\
\hline RC-0 & 1341 & 3.32 & $\mathrm{~N} / \mathrm{A}^{1}$ & 3.58 & N/A & 1139 & 1 \\
\hline HF-0 & 1485 & 21.99 & N/A & - & - & $-{ }^{2}$ & 1.11 \\
\hline VHF-0 & 1525 & 4.03 & N/A & 8.07 & N/A & 1287 & 1.14 \\
\hline AHF-0 & 1417 & 3.81 & N/A & 7.02 & N/A & 1174 & 1.06 \\
\hline RC-25 & 998 & 2.99 & 1.71 & 3.15 & 1.99 & 848 & 1 \\
\hline HF-25 & 1245 & 3.75 & 1.48 & - & - & - & 1.25 \\
\hline VHF-25 & 1189 & 3.80 & 1.57 & 8.17 & 6.14 & 911 & 1.19 \\
\hline AHF-25 & 1083 & 3.73 & 2.29 & 7.60 & 7.01 & 759 & 1.09 \\
\hline RC-50 & 755 & 3.06 & 2.20 & 3.38 & 2.70 & 641 & 1 \\
\hline HF-50 & 825 & 3.67 & 2.56 & 26.96 & 27.94 & 697 & 1.09 \\
\hline VHF-50 & 889 & 4.13 & 3.23 & 10.32 & 8.34 & 737 & 1.18 \\
\hline AHF-50 & 862 & 3.78 & 2.50 & 8.79 & 6.65 & 696 & 1.14 \\
\hline
\end{tabular}

${ }^{1}$ The lateral displacement is not applicable in cases of concentric loading

${ }^{2}$ Data was lost due to an accident during testing 
Table 4

Calculation of ductility

\begin{tabular}{lcccc}
\hline Specimen & \multicolumn{2}{c}{ Axial displacement (mm) } & Ductility & $\begin{array}{c}\text { Normalized } \\
\text { ductility }\end{array}$ \\
\cline { 2 - 3 } & $\begin{array}{c}\text { at yield } \\
\text { load }\end{array}$ & at 85\% $\mathrm{P}_{\max }$ & & \\
\cline { 2 - 4 } & $\Delta_{\mathrm{y}}$ & $\Delta_{85 \% \text { Pmax }}$ & $\begin{array}{c}\Delta_{85 \% \text { Pmax }} \\
/ \Delta \mathrm{y}\end{array}$ & \\
\hline RC-0 & 2.80 & 3.58 & 1.3 & 1.0 \\
HF-0 & 3.83 & 22.98 & 6.0 & 4.7 \\
VHF-0 & 2.92 & 8.05 & 2.8 & 2.2 \\
AHF-0 & 2.75 & 6.76 & 2.5 & 1.9 \\
\hline RC-25 & 2.62 & 3.15 & 1.2 & 1.0 \\
HF-25 & N/A & N/A & N/A & N/A \\
VHF-25 & 2.92 & 6.07 & 2.1 & 1.7 \\
AHF-25 & 3.05 & 5.87 & 1.9 & 1.6 \\
\hline RC-50 & 2.59 & 3.38 & 1.3 & 1.0 \\
HF-50 & 2.78 & 26.89 & 9.7 & 7.4 \\
VHF-50 & 2.78 & 8.52 & 3.1 & 2.3 \\
AHF-50 & 2.94 & 7.89 & 2.7 & 2.1 \\
\hline
\end{tabular}

${ }^{1}$ Data was lost due to an accident during testing 
Table 5

Summary of theoretical calculations

\begin{tabular}{|c|c|c|c|c|c|c|c|}
\hline \multirow[t]{2}{*}{ Group } & Eccentricity & $\begin{array}{c}\text { Theoretical } \\
\text { max. load } \\
\mathrm{P}_{\text {theo. }} \\
\end{array}$ & $\begin{array}{c}\text { Bending } \\
\text { moment } \\
\mathrm{M}_{\text {theo. }}=\mathrm{P}_{\text {theo. }} \mathrm{e} \\
\end{array}$ & $\begin{array}{c}\text { Experimental } \\
\text { max. load } \\
\mathrm{P}_{\text {expt. }} \\
\end{array}$ & $\begin{aligned} & \mathrm{M}_{\mathrm{I}} \\
= & \mathrm{P}_{\text {expt. }} \mathrm{e}\end{aligned}$ & $\begin{array}{c}\mathrm{M}_{\mathrm{II}} \\
=\mathrm{P}_{\text {expt. }}\left(\mathrm{e}^{+}+\delta\right)\end{array}$ & Difference \\
\hline & $\mathrm{mm}$ & $\mathrm{kN}$ & kNm & $\mathrm{kN}$ & $\mathrm{kNm}$ & $\mathrm{kNm}$ & $\%$ \\
\hline \multirow[t]{3}{*}{$\mathrm{RC}$} & 0 & 1274 & 0 & 1341 & 0 & 0 & 5.3 \\
\hline & 25 & 962 & 24.1 & 998 & 25.0 & 26.7 & 3.8 \\
\hline & 50 & 741 & 37.1 & 755 & 37.7 & 39.4 & 1.8 \\
\hline \multirow[t]{3}{*}{$\mathrm{HF}$} & 0 & 1535 & 0 & 1485 & 0 & 0 & -3.2 \\
\hline & 25 & 1132 & 28.3 & 1245 & 31.1 & 33.0 & 10.0 \\
\hline & 50 & 890 & 44.5 & 825 & 41.3 & 43.4 & -7.3 \\
\hline \multirow[t]{3}{*}{ VHF } & 0 & 1452 & 0 & 1525 & 0 & 0 & 5.0 \\
\hline & 25 & 1076 & 26.9 & 1189 & 29.7 & 31.6 & 10.5 \\
\hline & 50 & 845 & 42.3 & 889 & 44.4 & 47.3 & 5.2 \\
\hline \multirow[t]{3}{*}{ AHF } & 0 & 1366 & 0.00 & 1417 & 0 & 0 & 3.8 \\
\hline & 25 & 1018 & 25.5 & 1083 & 27.1 & 29.6 & 6.4 \\
\hline & 50 & 795 & 39.8 & 862 & 43.1 & 45.2 & 8.4 \\
\hline
\end{tabular}


Table 6

Theoretical and experimental strains of longitudinal steel bars at maximum load

\begin{tabular}{ccccccc}
\hline \multirow{2}{*}{ Specimen } & \multicolumn{3}{c}{$\begin{array}{c}\text { Strain of bars in compression side }(\mu \varepsilon) \\
\text { (Average value of SG3 and SG4) }\end{array}$} & \multicolumn{3}{c}{$\begin{array}{c}\text { Strain of bars on tension side }(\mu \varepsilon) \\
\text { (Average value of SG1and SG2) }\end{array}$} \\
\cline { 2 - 7 } & Theo. & Exp. & Difference (\%) & Theo. & Exp. & Difference $(\%)$ \\
\hline RC-0 & 2900 & 3156 & 8.8 & & & \\
RC-25 & 2420 & 3073 & 27.0 & 213 & 354 & 66.2 \\
RC-50 & 2390 & 3044 & 27.4 & 0 & 29 & $\cong 0{ }^{1}$ \\
\hline HF-0 & 2900 & N/A & N/A & & & \\
HF-25 & 3880 & 3149 & -18.8 & 926 & 856 & -7.6 \\
HF-50 & 3730 & 4302 & 15.3 & 0 & 16 & $\cong 0$ \\
\hline VHF-0 & 2900 & 3305 & 14.0 & & & \\
VHF-25 & 3124 & 3501 & 12.1 & 263 & 358 & 36.1 \\
VHF-50 & 3080 & 3698 & 20.1 & 0 & 57 & $\cong 0$ \\
\hline AHF-0 & 2900 & 3346 & 15.4 & & & \\
AHF-25 & 2621 & 3477 & 32.0 & 234 & 447 & 91.0 \\
AHF-50 & 2550 & 3243 & 27.2 & 0 & 12 & $\cong 0$ \\
\hline
\end{tabular}

${ }^{1}$ The experimental strains of bars SG1, SG2 at $50 \mathrm{~mm}$ eccentric loading were very close to zero.

Note: Refer to Fig. 12 for locations of Strain Gages SG1 - SG4 
Table 7

Strain of the tie at mid-height of column (Strain gages SG5 and SG6)

\begin{tabular}{ccccccccc}
\hline Specimen & \multicolumn{2}{c}{$\begin{array}{c}\text { At yield load } \\
(\mu \varepsilon)\end{array}$} & \multicolumn{2}{c}{$\begin{array}{c}\text { At max. load } \\
(\mu \varepsilon)\end{array}$} & $\begin{array}{c}\text { At } 85 \% \text { of max. load } \\
(\mu \varepsilon)\end{array}$ & $\begin{array}{c}\text { At load corr. to } \\
\text { ultimate strain } \\
(\mu \varepsilon)\end{array}$ \\
& SG5 & SG6 & SG5 & SG6 & SG5 & SG6 & SG5 & SG6 \\
\hline RC-0 & 752 & 563 & 1261 & 770 & 2761 & 956 & 2761 & 956 \\
HF-0 & 1129 & 450 & 1861 & 1599 & 10237 & 8987 & failed ${ }^{1}$ & failed \\
VHF-0 & 913 & 593 & 1413 & 935 & 1298 & 888 & 1125 & 860 \\
AHF-0 & 960 & 639 & 1915 & 1234 & 2448 & 1517 & 2421 & 1448 \\
\hline RC-25 & 130 & 786 & 135 & 1153 & 97 & 1257 & 97 & 1257 \\
HF-25 & N/A & N/A & 158 & 1426 & N/A & N/A & 79 & 1347 \\
VHF-25 & 79 & -3 & 91.6 & - & 82 & - & 76 & - \\
AHF-25 & 82 & 696 & 101 & 1356 & 362 & 838 & 472 & 724 \\
\hline RC-50 & 13 & 592 & 13 & 813 & 7 & 841 & 7 & 841 \\
HF-50 & 10 & 520 & 19 & 856 & 207 & 1156 & 204 & 1150 \\
VHF-50 & 8 & 531 & 19 & 820 & 19 & 808 & 21 & 714 \\
AHF-50 & 0 & 546 & 2 & 749 & 27 & 758 & 36 & 730
\end{tabular}

${ }^{1}$ At that point the strain gage already reached limit strain value (1\% for strain gages glued on tie) and failed.

${ }^{2}$ The strain gage values were not applicable because Specimen HF-25 got accident during testing.

${ }^{3}$ The strain gage broke.

Note: Refer to Fig. 12 for locations of Strain Gage SG5 and SG6 
Figure 1

Figure 1
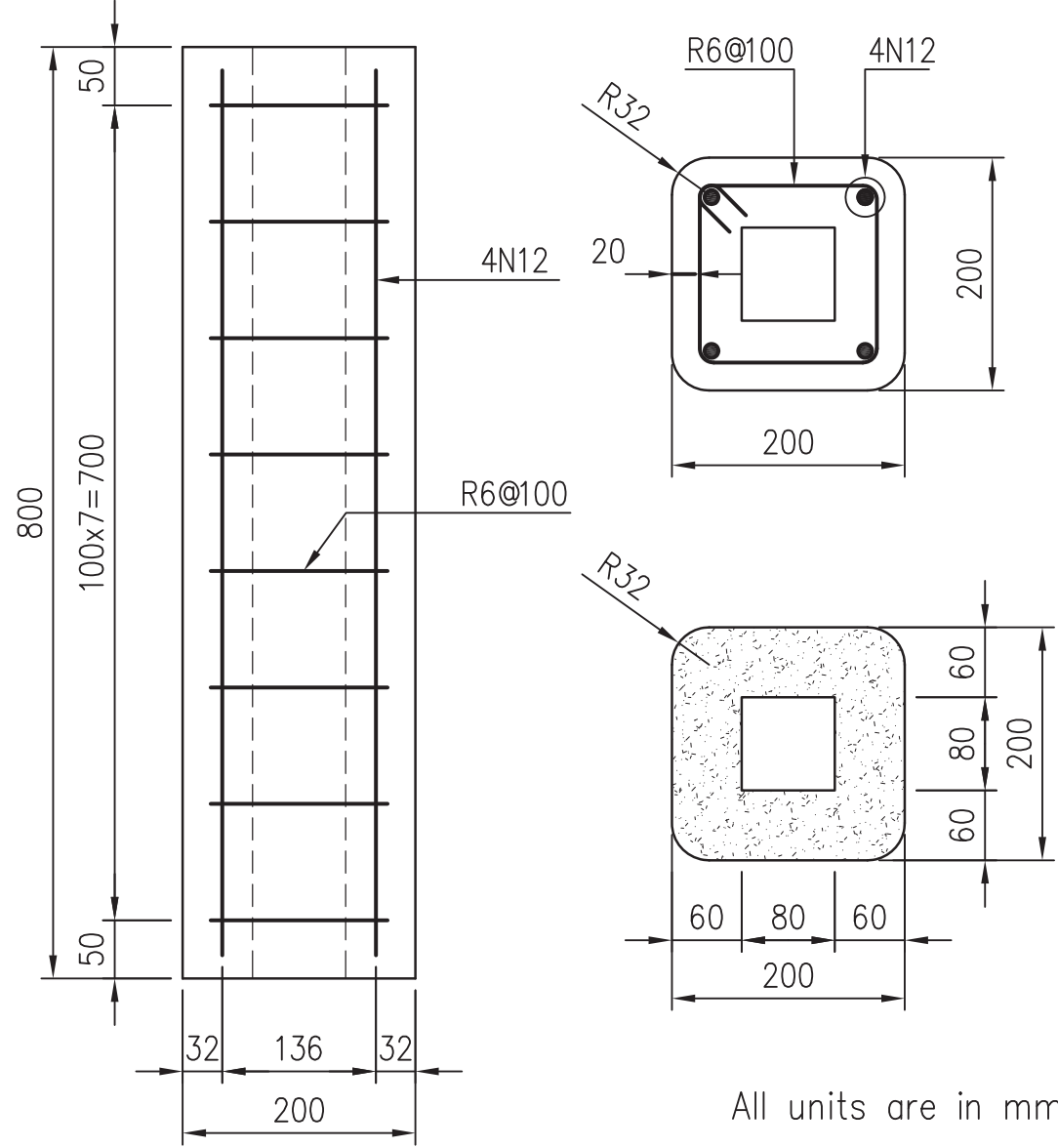

All units are in $\mathrm{mm}$. 
Figure

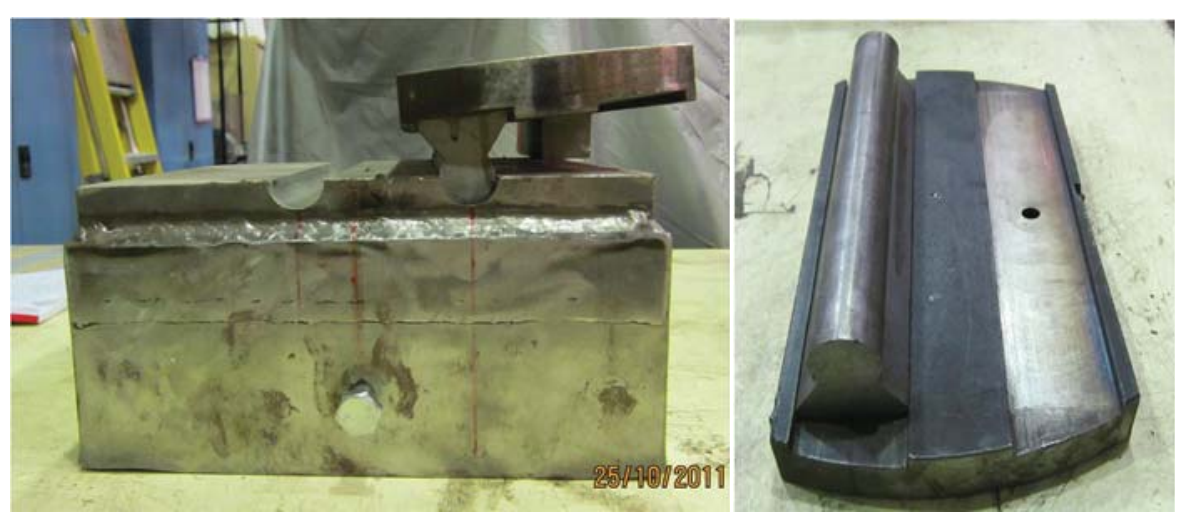

Figure 2 
Figure 3

Figure 3

PLAN VIEW

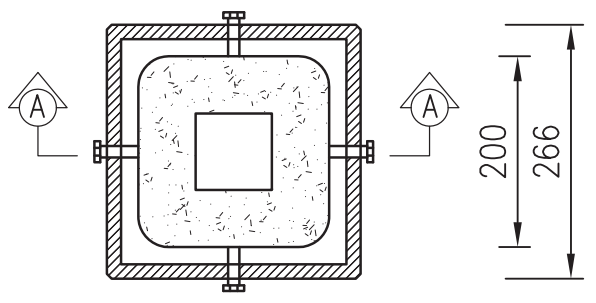

$\mid-1-$

SECTION A-A

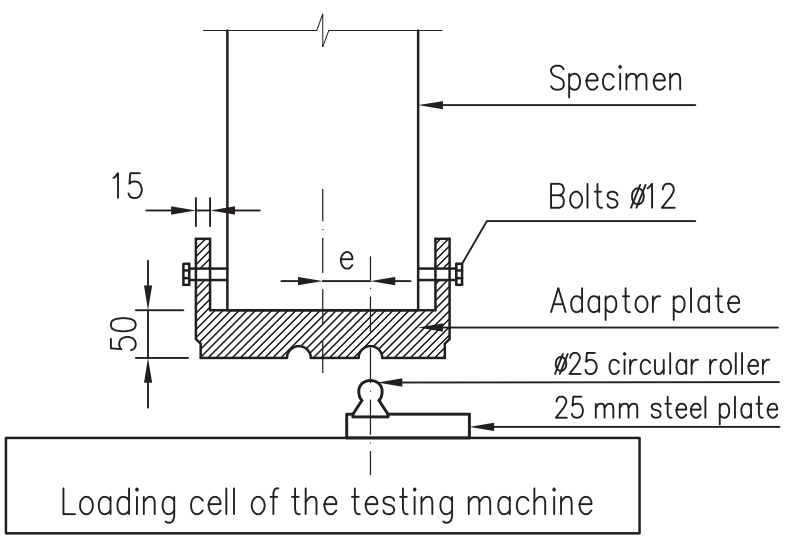


Figure 4

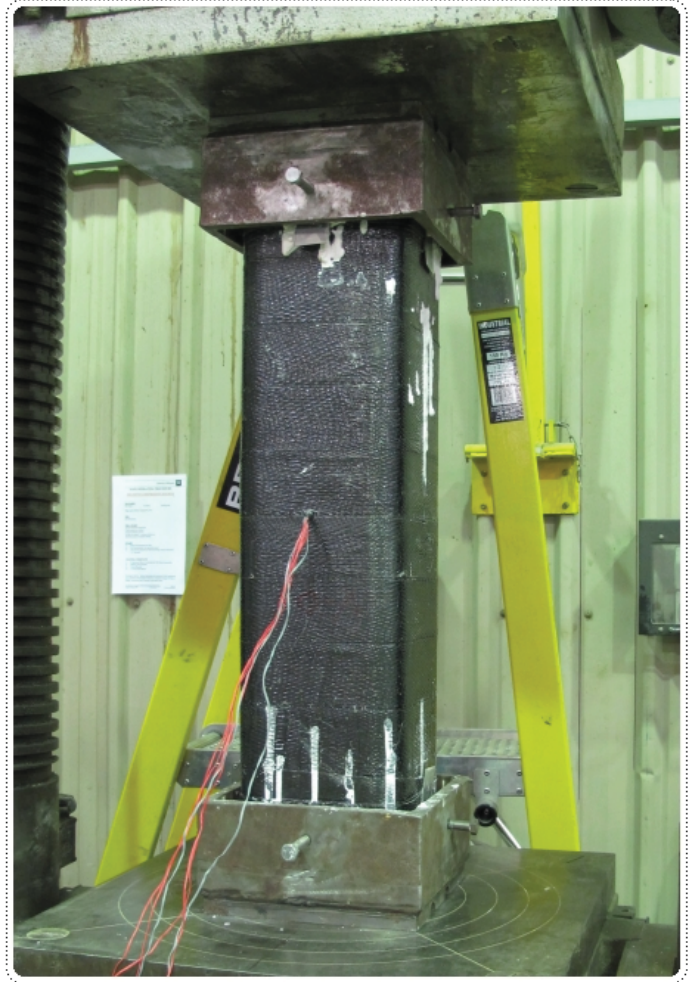

A concentrically loaded specimen

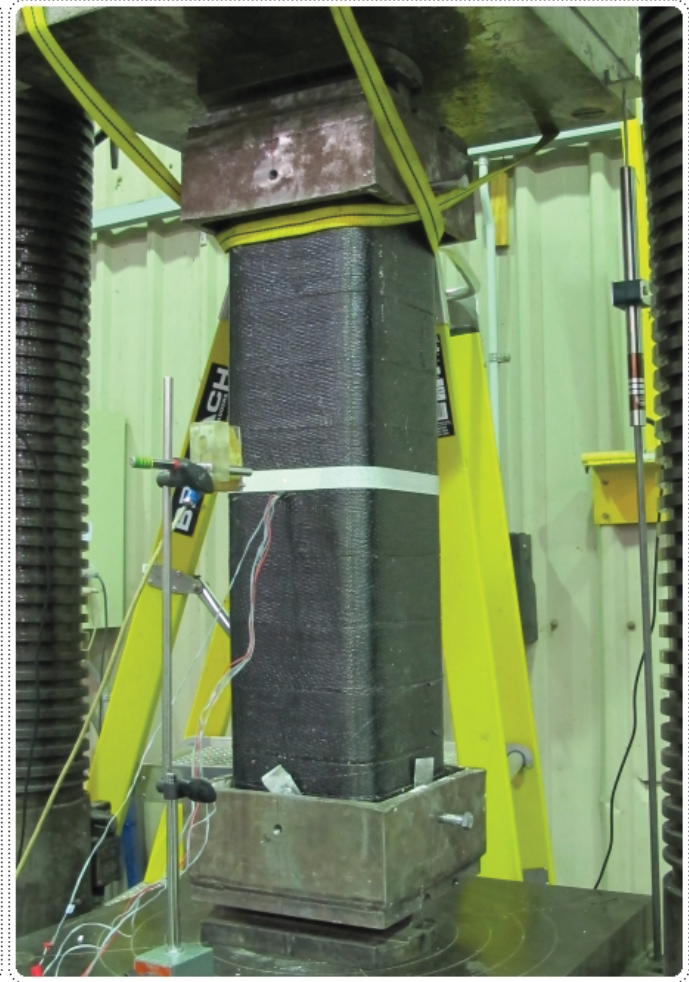

An eccentrically loaded specimen 
Figure 5

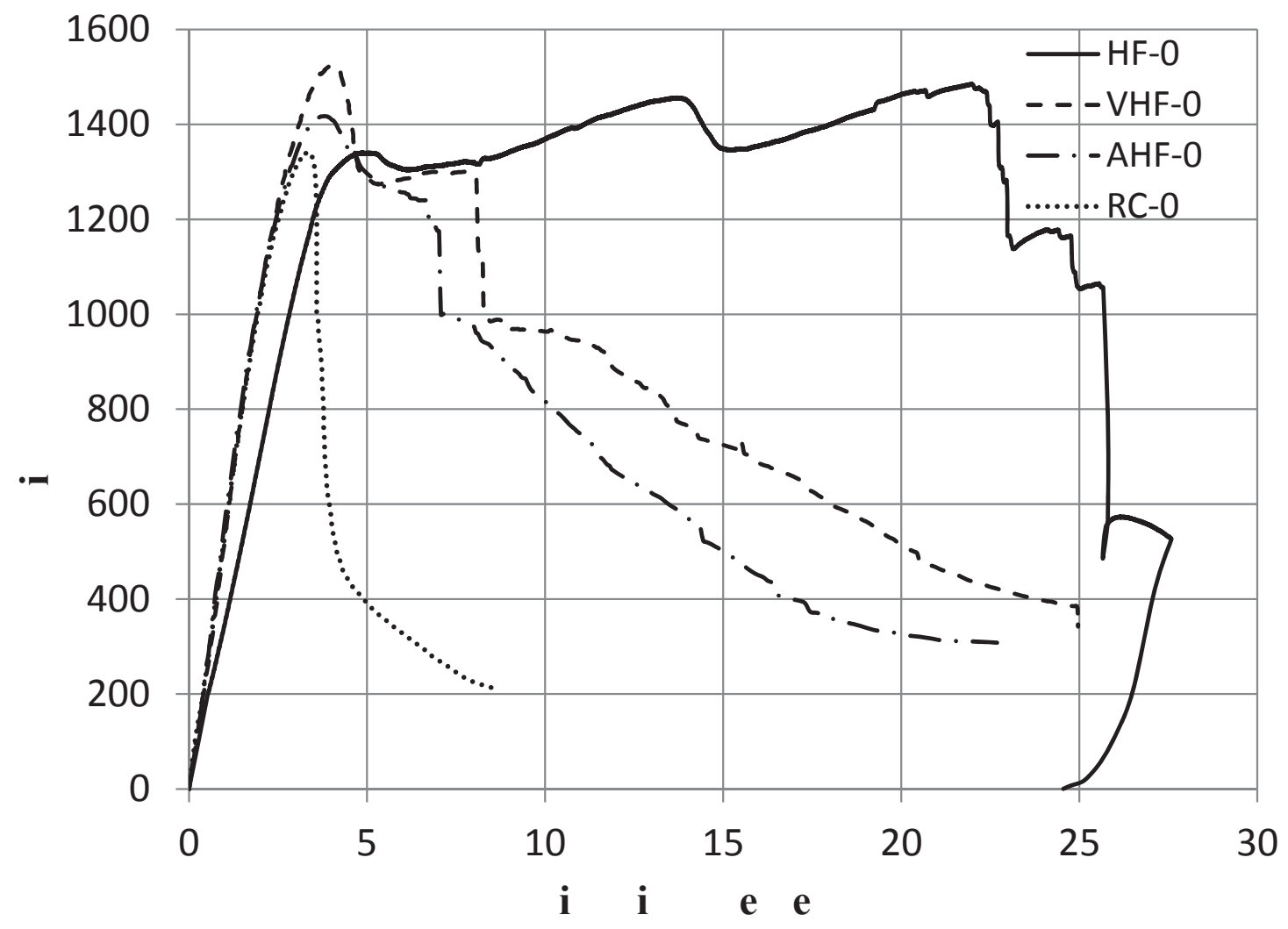


Figure 6

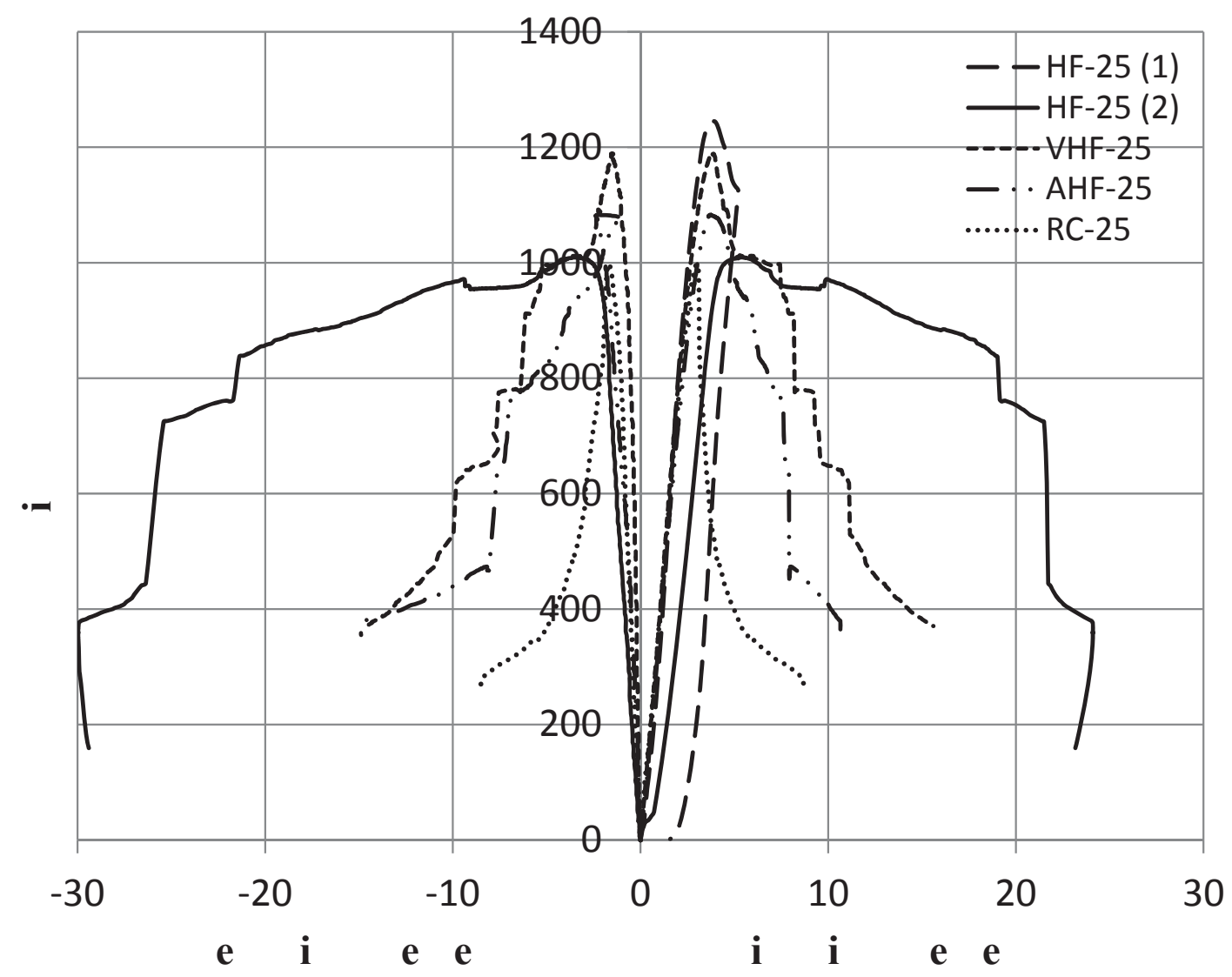


Figure 5

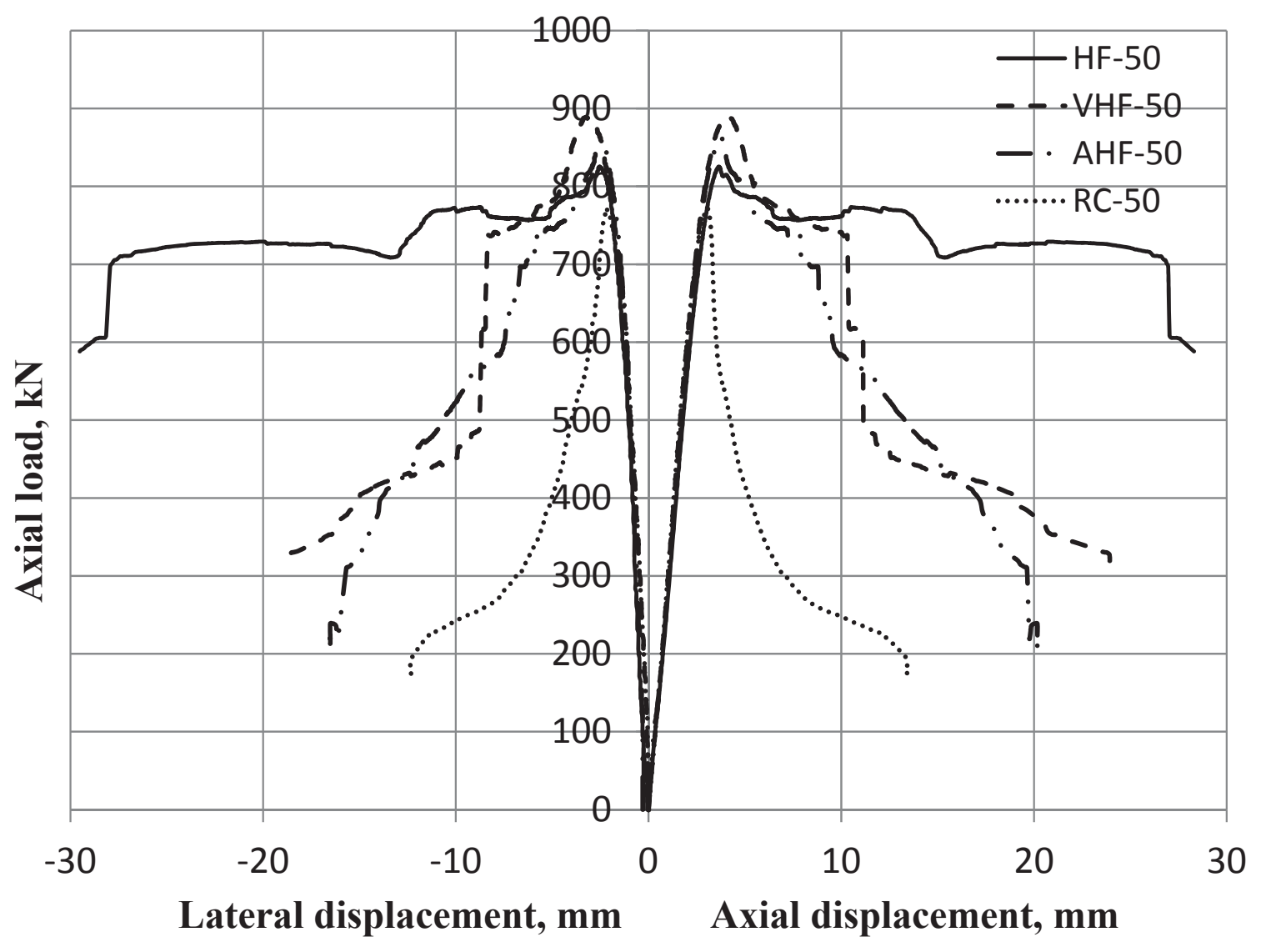




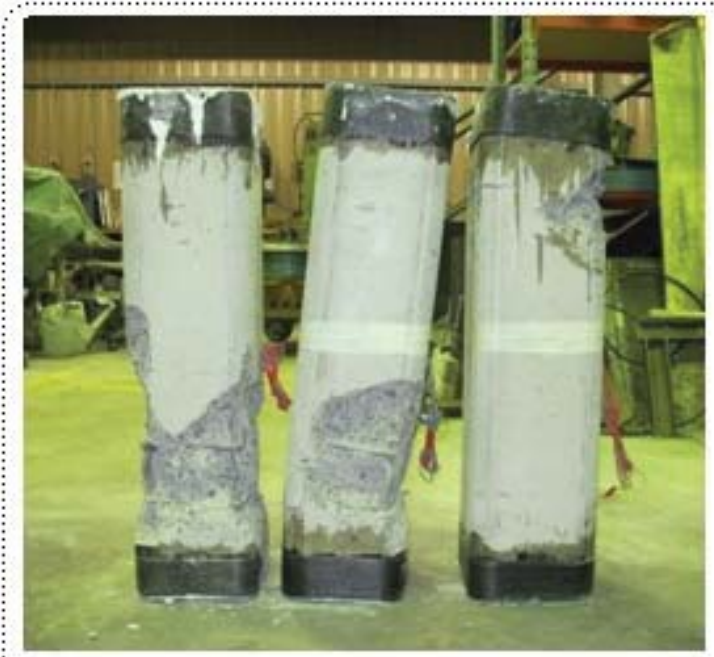

$\mathrm{RC}$ columns

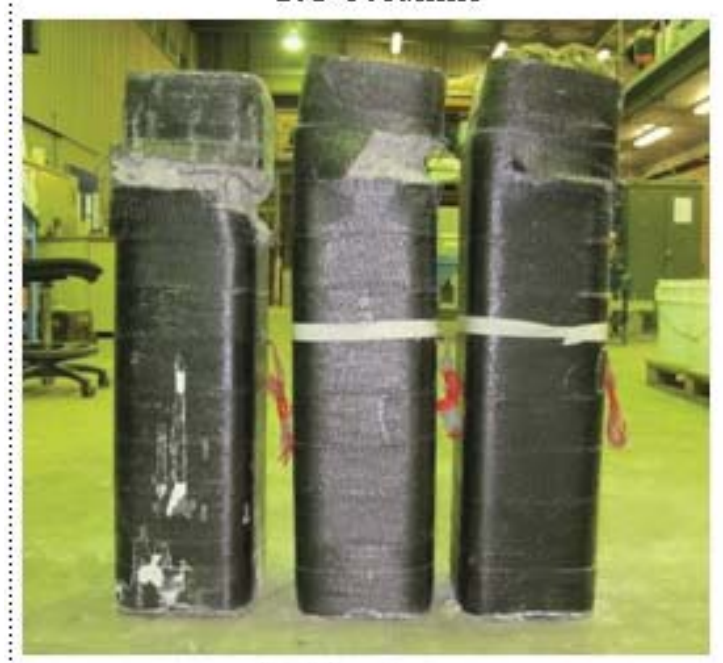

VHF columns

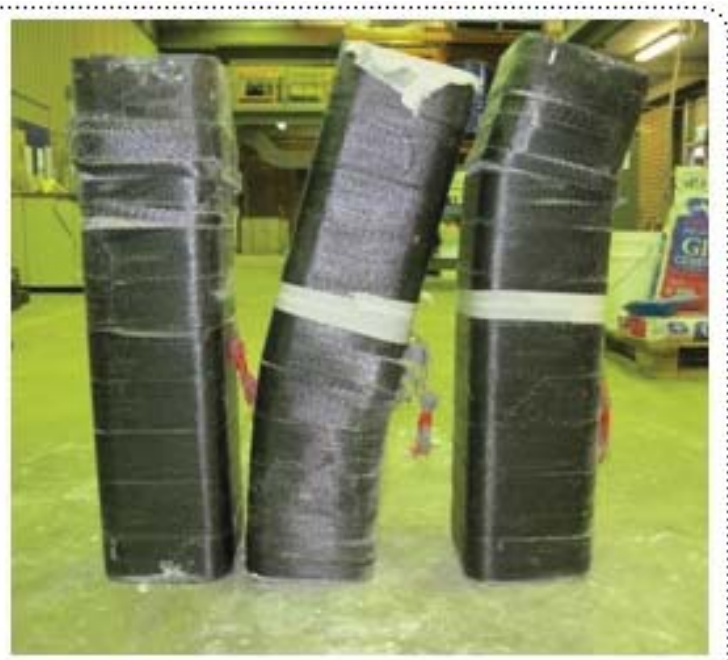

HF columns

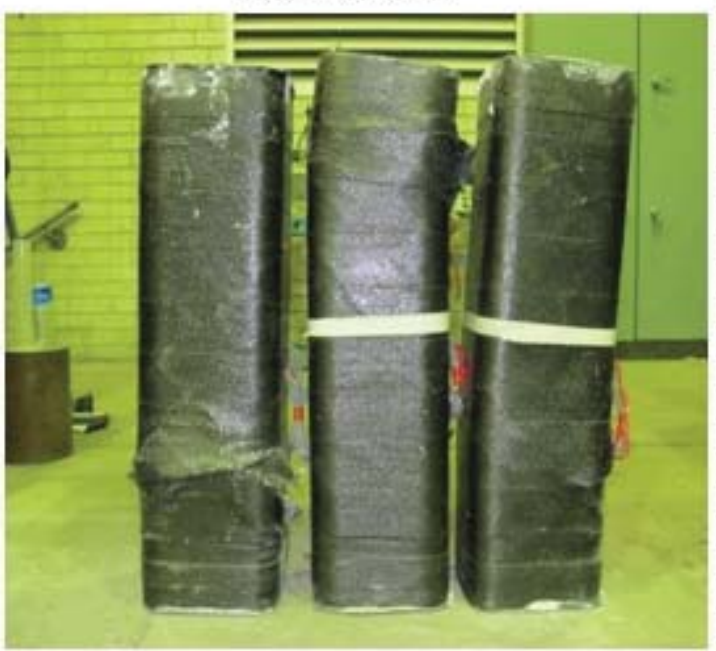

AHF columns 


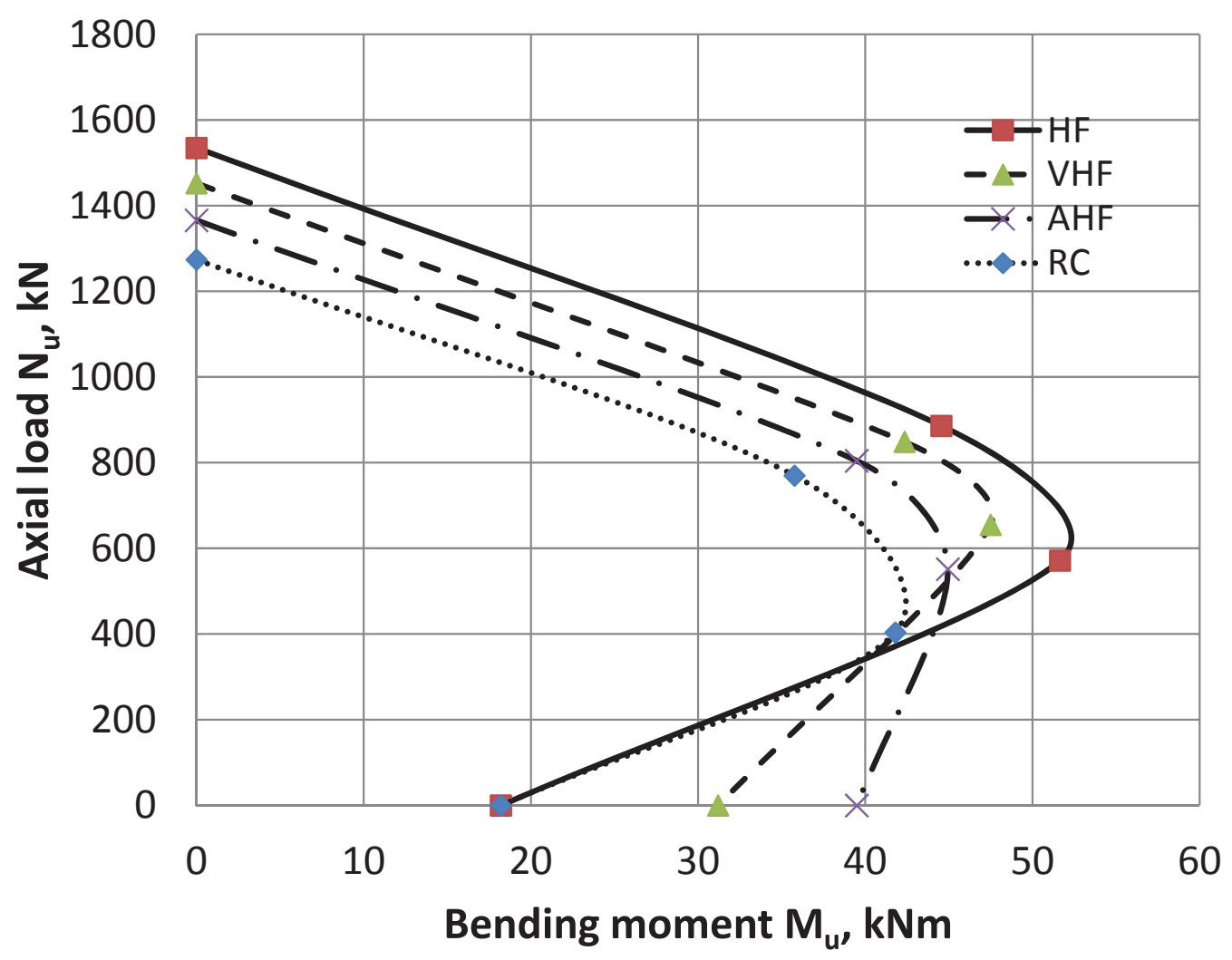




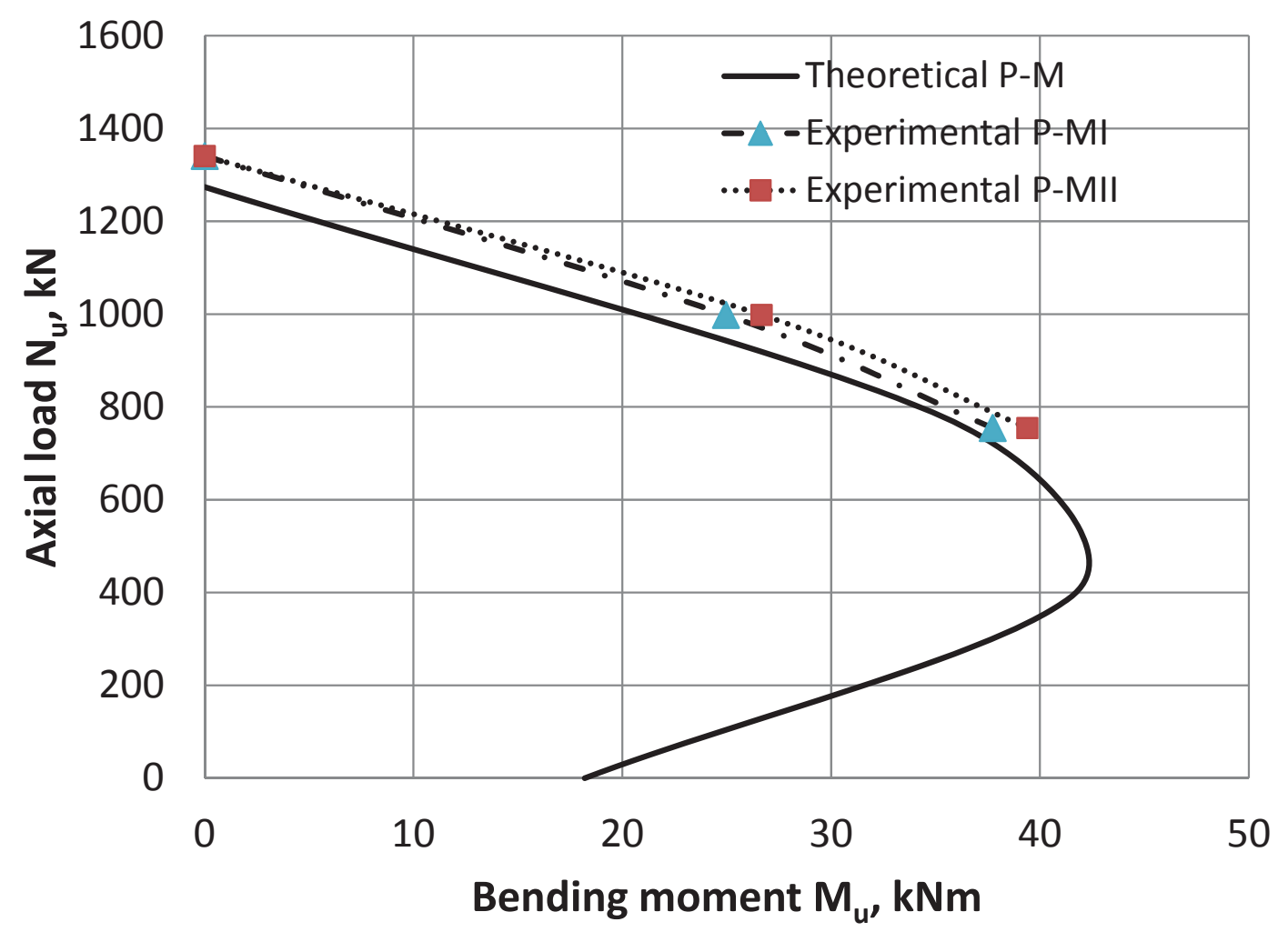




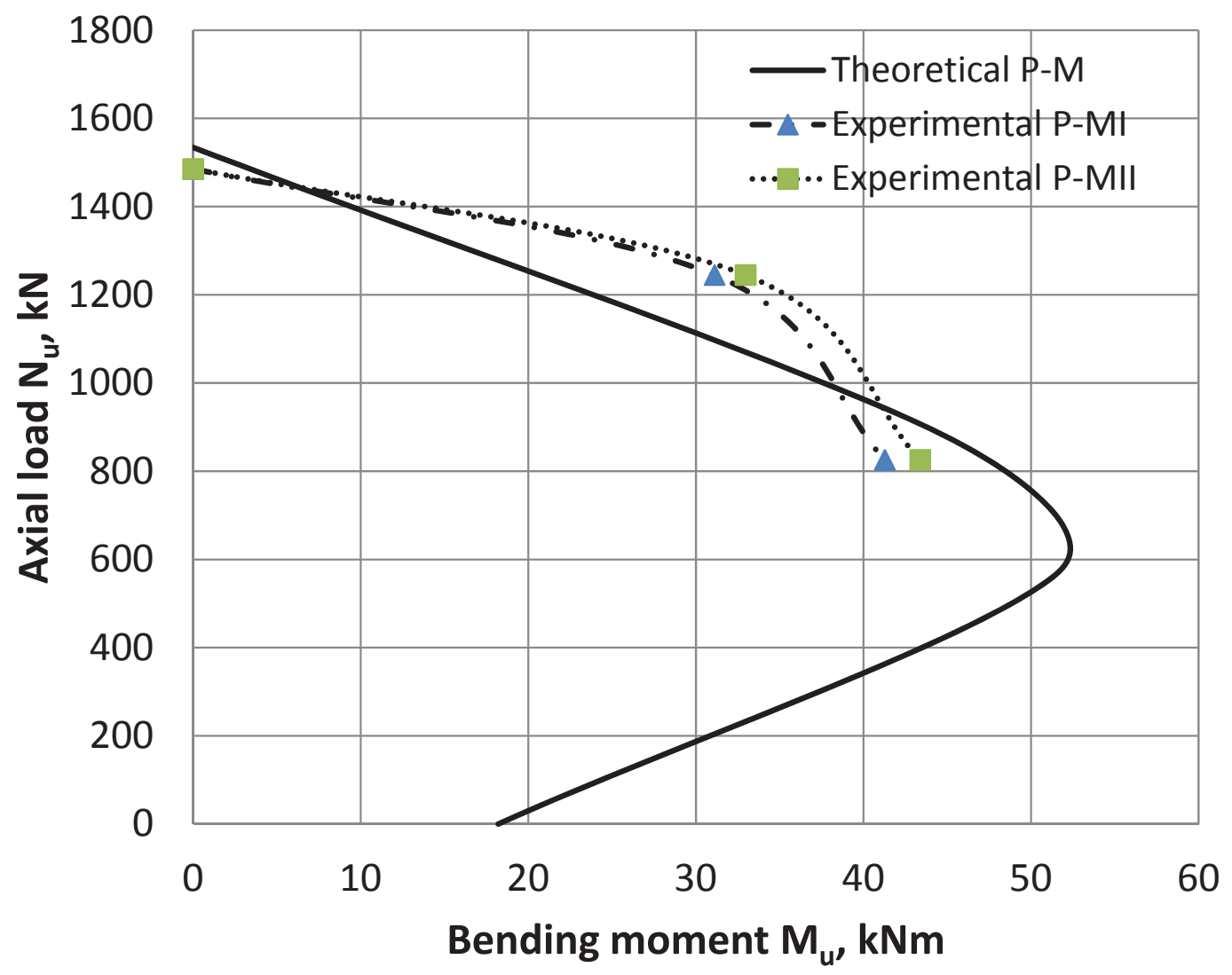


Figure 12

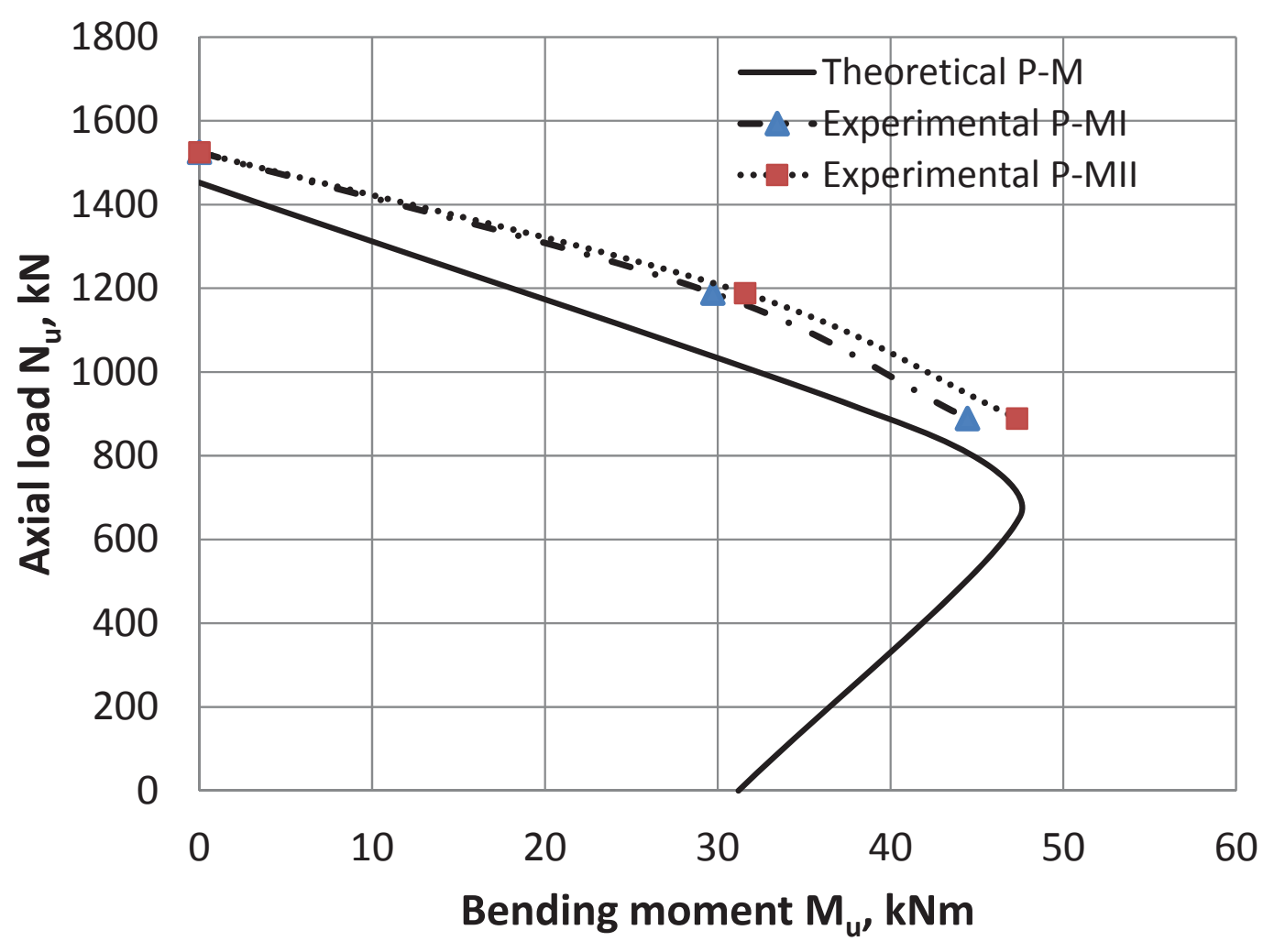


Figure 13

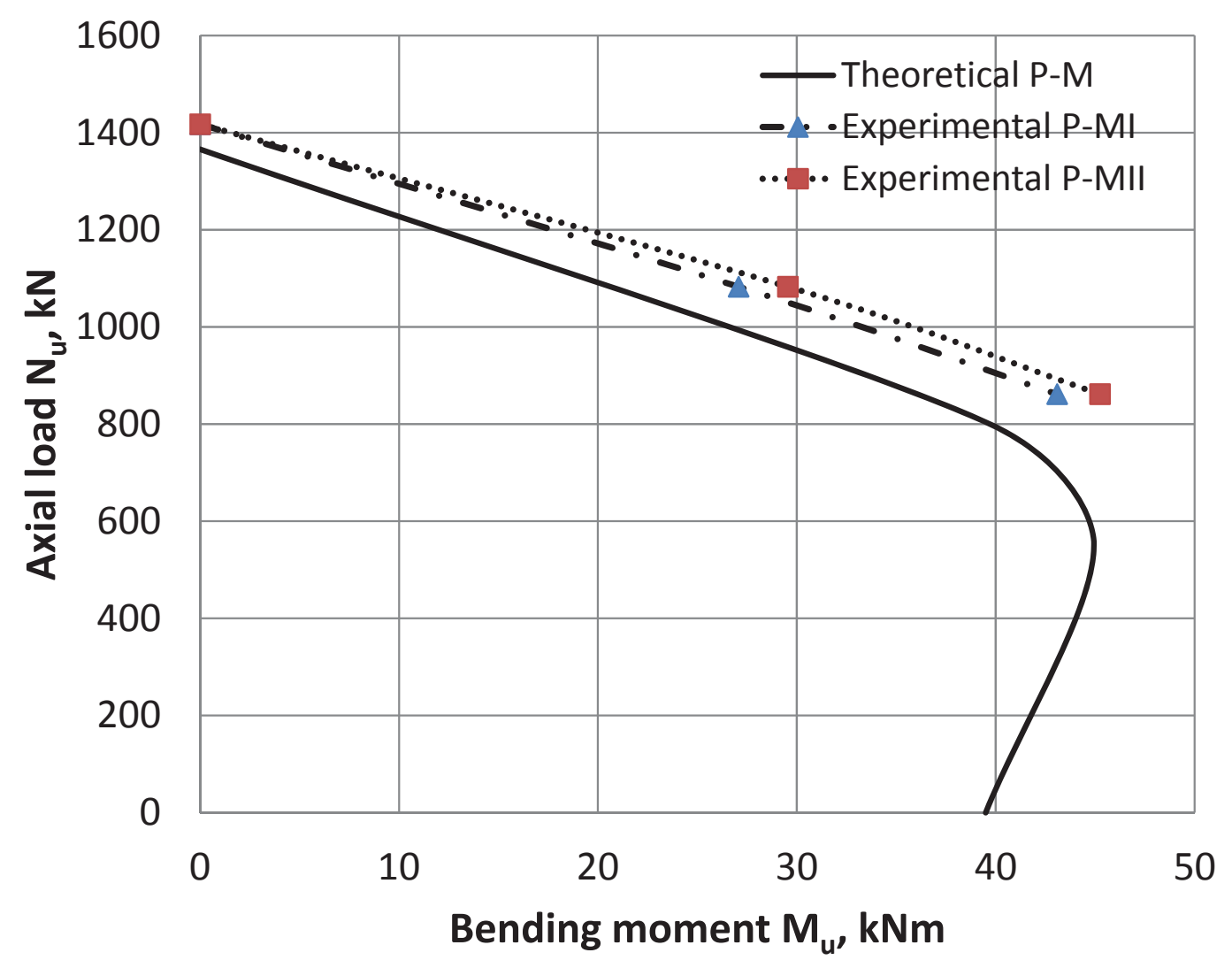


Figure 14

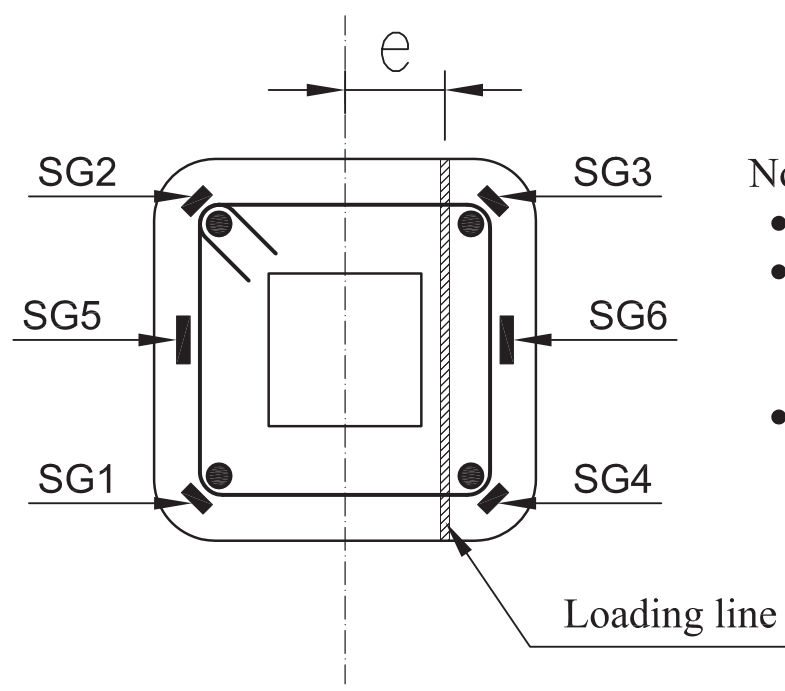

Notes:

- $\mathrm{e}$ is the eccentricity

- Strain gages SG1, SG2, SG3, SG4 were placed on at mid-height of longitudinal steel bars

- Strain gages SG5, SG6 were placed on a tie at mid-height of the column 